\title{
RNA-seq based identification and mutant validation of gene targets related to ethanol resistance in cyanobacterial Synechocystis sp. PCC 6803
}

Jiangxin Wang ${ }^{1,2}$, Lei Chen ${ }^{1,2}$, Siqiang Huang ${ }^{1,2}$, Jie Liu ${ }^{1,2}$, Xiaoyue Ren ${ }^{1,2}$, Xiaoxu Tian ${ }^{1,2}$, Jianjun Qiao ${ }^{1,2}$ and Weiwen Zhang ${ }^{1,2^{*}}$

\begin{abstract}
Background: Fermentation production of biofuel ethanol consumes agricultural crops, which will compete directly with the food supply. As an alternative, photosynthetic cyanobacteria have been proposed as microbial factories to produce ethanol directly from solar energy and $\mathrm{CO}_{2}$. However, the ethanol productivity from photoautotrophic cyanobacteria is still very low, mostly due to the low tolerance of cyanobacterial systems to ethanol stress.

Results: To build a foundation necessary to engineer robust ethanol-producing cyanobacterial hosts, in this study we applied a quantitative transcriptomics approach with a next-generation sequencing technology, combined with quantitative reverse-transcript PCR (RT-PCR) analysis, to reveal the global metabolic responses to ethanol in model cyanobacterial Synechocystis sp. PCC 6803. The results showed that ethanol exposure induced genes involved in common stress responses, transporting and cell envelope modification. In addition, the cells can also utilize enhanced polyhydroxyalkanoates (PHA) accumulation and glyoxalase detoxication pathway as means against ethanol stress. The up-regulation of photosynthesis by ethanol was also further confirmed at transcriptional level. Finally, we used gene knockout strains to validate the potential target genes related to ethanol tolerance.

Conclusion: RNA-Seq based global transcriptomic analysis provided a comprehensive view of cellular response to ethanol exposure. The analysis provided a list of gene targets for engineering ethanol tolerance in cyanobacterium Synechocystis.
\end{abstract}

Keywords: Ethanol, Tolerance, Transcriptomics, Synechocystis

\section{Background}

Ethanol currently constitutes $99 \%$ of all biofuels in the United States. E-10 Unleaded, a blend of $10 \%$ ethanol and $90 \%$ ordinary gasoline, has been used in the U.S. for more than 25 years. Additionally, a blend of $85 \%$ ethanol and $15 \%$ ordinary gasoline (known as E-85) is rapidly growing in popularity [1]. The 3.4 billion gallons of ethanol blended into gasoline in 2004 amounted to about $2 \%$ of all gasoline sold by volume and 1.3\% (2.5 x $1017 \mathrm{~J})$ of its energy content [1]. Greater quantities of ethanol are

\footnotetext{
* Correspondence: wwzhang8@tju.edu.cn

${ }^{1}$ School of Chemical Engineering \& Technology, Tianjin University, Tianjin 300072, People's Republic of China

${ }^{2}$ Key Laboratory of Systems Bioengineering, Ministry of Education, Tianjin 300072, People's Republic of China
}

expected to be used as a motor fuel in the future because of the federal policies, such as the "Twenty-inTen" program that proposes to cut gasoline consumption and greenhouse gas emissions from motor vehicles by 20 percent over the next 10 years. Large-scale ethanol production utilizes yeast or bacteria, such as Saccharomyces cerevisiae and Zymomonas mobilis to ferment sugar syrups [2]. The process has seen significant progress in recent years: inhibitor sensitivity, product tolerance, ethanol yield and specific ethanol productivity have been improved in modern industrial strains to the degree that up to $20 \%(v / v)$ of ethanol can be produced from starch-derived glucose [3]. However, since the large-scale ethanol fermentation consumes significant

\section{() Biomed Central}


amount of agricultural crops, which competes directly with the world food supply, and its increased production has been blamed for the food price increases in recent years.

Photosynthetic cyanobacteria have recently attracted significant attention as a 'microbial factory' to produce biofuels and fine chemicals due to their capability to utilize solar energy and $\mathrm{CO}_{2}$ as sole energy and carbon sources, respectively [4]. By expressing a bacterial pyruvate decarboxylase $(p d c)$ and alcohol dehydrogenase (adh) from the bacterium Z. mobilis in the cyanobacterium Synechococcus sp. PCC 7942, Deng and Coleman (1999) obtained a recombinant microorganism which can produce up to $230 \mathrm{mg} / \mathrm{L}$ ethanol directly from $\mathrm{CO}_{2}$ within 4 weeks of growth [5]. More recently, a genomescale metabolic network model of Synechocystis sp. PCC 6803 was used to improve cyanobacterial ethanol production up to $690 \mathrm{mg} / \mathrm{L}$ in a week [6]. Although still at very low productivity, these works clearly demonstrated that photoautotrophic cyanobacteria could potentially be engineered for a direct conversion of solar energy and $\mathrm{CO}_{2}$ into biofuel products such as ethanol.

One of the key factors responsible for the low ethanol productivity is the low tolerance of photosynthetic systems to ethanol $[7,8]$. Ethanol can interfere with cell membrane's ability to act as a barrier, and interrupt key cellular processes such as protein biosynthesis, energy transduction and transport [8]. Although ethanol tolerance mechanism and application of ethanol-tolerant strains for enhanced production have been reported in native-producing yeasts and bacteria, current knowledge on ethanol tolerance in cyanobacteria is not enough to guide a rational engineering of more robust cyanobacterial hosts. To address this issue, we previously applied a quantitative iTRAQ LC-MS/MS proteomics approach to determine the responses of model cyanobacterial Synechocystis sp. PCC 6803 to ethanol [9]. The analysis showed that the Synechocystis cells employed a combination of induced common stress response, modifications of cell membrane and envelope, and induction of multiple transporters and cell mobility-related proteins as major protection mechanisms against ethanol toxicity [9]. To further decipher responses at transcriptional level, in this study, we applied a quantitative transcriptomics approach with a next-generation sequencing technology, combined with quantitative reverse-transcript PCR (RT-PCR) analysis, to reveal the global metabolic responses to ethanol in Synechocystis sp. PCC 6803 [10]. We then compared the transcriptomics data with proteomic data obtained previously to further confirm the targets related to ethanol tolerance [9]. Finally, we constructed several knockout mutants of ethanol-induced genes to validate their potential application as targets for engineering ethanol tolerance. The
RNA-seq transcriptomics analysis not only further confirmed the cellular responses revealed from previous proteomics analysis, but also showed that Synechocystis cells can also utilize enhanced PHA accumulation and glyoxalase detoxication pathway as means against ethanol stress. The study provided a list of gene targets for tolerance engineering in cyanobacterium Synechocystis.

\section{Results and discussion}

\section{Ethanol effects on Synechocystis sp. PCC 6803}

To make the transcriptomics data comparable with previous proteomics data, we used the identical sampling conditions for transcriptomics as our previous proteomics analysis [9]. As described before, the growth of Synechocystis sp. PCC 6803 supplemented with 0, 1.25, 1.50 and $2.00 \%$ ethanol was assessed to determine an appropriate ethanol concentration for proteomic studies. The results showed that the concentration of ethanol that caused a $50 \%$ growth decrease was found to be $1.50 \%(v / v)$ at $24 \mathrm{~h}$ (corresponding to middleexponential phase), and was selected for the analysis in this study [9]. Cell morphology under ethanol-treated and control conditions was compared under microscope, and the results showed that visible aggregation of large number of cells was found after $24 \mathrm{~h}$ treatment even at a concentration of $1.50 \%$, compared with the clearly individual cells in the control (data not shown). For transcriptomic analysis, two independent cultivations for both control (no ethanol) and 1.5\% ethanol-treated experiments were conducted, and cells were collected by centrifugation $\left(8,000 \times g\right.$ for $10 \mathrm{~min}$ at $\left.4^{\circ} \mathrm{C}\right)$ at $24 \mathrm{~h}, 48 \mathrm{~h}$ and $72 \mathrm{~h}$, resulting two biological replicates for each time point. The time points of sampling were corresponded to middle-exponential, exponential-stationary transition and stationary phases of the cell growth, respectively [9].

\section{Overview of transcriptomics analysis}

A total of 112-million raw sequencing reads was obtained from the RNA-seq transcriptomics analysis of nine samples, with average reads of 12.5-million reads per sample. After a two-step data filtering process, first to eliminate reads with low-quality bases (such as multiple N) and reads shorter than $20 \mathrm{bp}$, and then to eliminate sequence reads mapped to non-coding RNA of Synechocystis sp. PCC 6803 [10], a total of 20.4-million qualified mRNA-based sequence reads were identified (Table 1). Except for the control sample at $24 \mathrm{~h}$ (Control-24 h) which has a genome mapping ratio of $57 \%$, all other samples have mapping ratio larger than $60 \%$, with the control sample at $72 \mathrm{~h}$ larger than $80 \%$. Reproducibility between biological replicates of ethanol-treated samples at three time points was plotted (Figure 1), with correlation coefficient around 0.98-0.99, indicating the 
Table 1 Statistics of RNA-Seq transcriptomics analysis

\begin{tabular}{lcccc}
\hline Sample ID & Raw sequences reads & Qualified mRNA reads & Genome-mapped Reads & Mapping ratio \\
\hline Control-24 h & $18,859,596$ & $5,552,572$ & $3,177,168$ & $57.22 \%$ \\
Control-48 h & $10,589,107$ & $2,331,738$ & $1,784,966$ & $76.55 \%$ \\
Control-72 h & $11,249,884$ & $3,026,360$ & $2,455,571$ & $81.14 \%$ \\
Ethanol-24 h-r1 & $12,277,943$ & $3,211,398$ & $1,985,207$ & $61.82 \%$ \\
Ethanol-24 h-r2 & $13,736,430$ & $3,755,422$ & $2,323,029$ & $61.86 \%$ \\
Ethanol-48 h-r1 & $13,384,367$ & $4,041,104$ & $2,453,989$ & $60.73 \%$ \\
Ethanol-48 h-r2 & $10,306,514$ & $2,934,288$ & $1,772,957$ & $60.42 \%$ \\
Ethanol-72 h-r1 & $11,883,271$ & $3,623,746$ & $2,363,916$ & $65.23 \%$ \\
Ethanol-72 h-r2 & $9,814,306$ & $3,160,336$ & $2,083,580$ & $65.93 \%$ \\
\hline
\end{tabular}

overall good quality of RNA sequencing. The sequence reads matched to all 3189 coding genes in Synechocystis sp. PCC 6803 genome (Additional file 1: Table S1), suggesting that the sequencing is deep enough to cover almost all species of transcripts in the cells. Abundance of the qualified mRNA-based raw sequence reads ranged from 1 to 341,135 for control samples, and from 1 to 154,326 for ethanol-treated samples, respectively, representing an expression dynamic range of $10^{5}$, which is higher than $10^{3-4}$ of typical microarray-based analyses [11,12]. Using Reads Per Kilobase of Gene per Million Mapped Reads (RPKM) as an index of the normalized transcript abundance [13], we identified the top expressed genes under the control and ethanoltreated conditions through the growth time course (Table 2). The top 50 expressed genes were found involved mostly in energy metabolism, including genes coding photosynthesis-related phycocyanin alpha subunit, phycocyanin beta subunit and photosystem I subunit XI and genes coding multiple subunits of ATP synthase, followed by genes encoding proteins synthesis such as multiple $50 \mathrm{~S}$ ribosomal proteins and elongation factor, and genes involved in $\mathrm{CO}_{2}$ fixation such as ribulose bisphosphate carboxylase genes, consistent well with previous analysis on highly expressed genes in Synechocystis [14,15]. Interestingly, we also found several genes encoding hypothetical proteins (ssl0483, slr0144, slr1470 and slr0373) were also among the top expressed genes, suggesting possible important physiological functions they may be responsible for. Although the exact function is still unknown, slr0144 has been suggested to encode a PSII-associated protein [16], and slr0373 forms an operon with slr0374 which has been found responsive to various environmental stresses [17].

Using a cutoff of 1.5-fold change in both biological replicates, we determined that 1874 and 274 genes were down- and up-regulated by ethanol, respectively. For the down-regulated genes, 1343, 596 and 830 genes were down-regulated at 24, 48 and $72 \mathrm{~h}$, respectively. Among them 167 genes were down-regulated in all three time points (Additional file 2: Table S2). Analysis of the functional category of the down-regulated genes was shown in Figure 2. The results showed that the most affected functional categories were "hypothetical proteins" and "unknown function", representing a total of more than $68 \%$ of all the down-regulated genes, consistent with the fact that nearly half of the Synechocystis

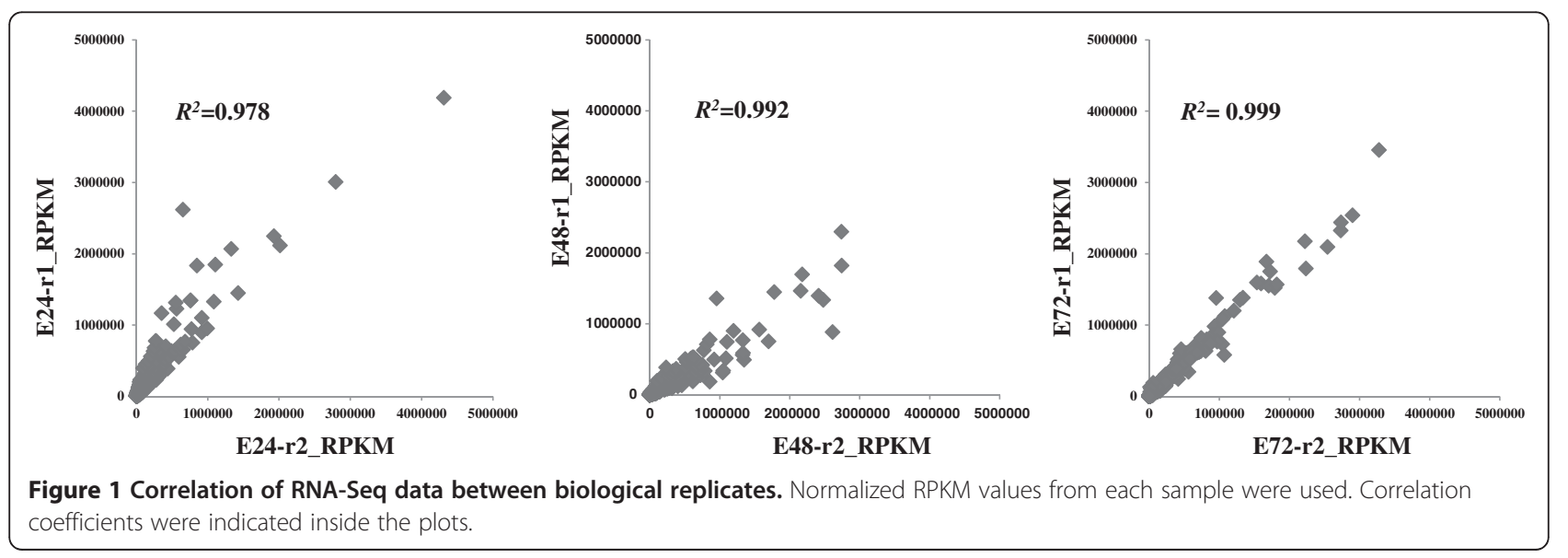


Table 2 Top 50 expressed genes based on normalized expression level (RPKM values)

\begin{tabular}{|c|c|c|c|c|c|c|c|c|c|c|c|}
\hline Gene ID & $\begin{array}{l}\text { Control- } \\
24 \mathrm{~h}\end{array}$ & $\begin{array}{l}\text { Control- } \\
48 \mathrm{~h}\end{array}$ & $\begin{array}{l}\text { Control- } \\
72 \mathrm{~h}\end{array}$ & $\begin{array}{l}\text { Ethanol- } \\
24 \mathrm{~h}-\mathrm{r} 1\end{array}$ & $\begin{array}{l}\text { Ethanol- } \\
24 \mathrm{~h}-\mathrm{r} 2\end{array}$ & $\begin{array}{c}\text { Ethanol- } \\
48 \mathrm{~h}-\mathrm{r} 1\end{array}$ & $\begin{array}{c}\text { Ethanol- } \\
48 \mathrm{~h}-\mathrm{r} 2\end{array}$ & $\begin{array}{l}\text { Ethanol- } \\
72 \mathrm{~h}-\mathrm{r} 1\end{array}$ & $\begin{array}{l}\text { Ethanol- } \\
72 \mathrm{~h}-\mathrm{r} 2\end{array}$ & Discription & Cellular role \\
\hline sll1744 & $7.42 \mathrm{E}+05$ & $8.96 \mathrm{E}+05$ & $9.57 \mathrm{E}+05$ & $6.14 \mathrm{E}+05$ & $6.66 \mathrm{E}+05$ & $6.65 E+05$ & $3.97 E+05$ & $7.24 \mathrm{E}+05$ & $6.49 E+05$ & $50 S$ ribosomal protein L1 & Protein synthesis \\
\hline sll1745 & $3.42 \mathrm{E}+06$ & $3.74 \mathrm{E}+06$ & $3.97 E+06$ & $2.80 \mathrm{E}+06$ & $3.01 \mathrm{E}+06$ & $2.74 \mathrm{E}+06$ & $1.82 \mathrm{E}+06$ & $2.90 \mathrm{E}+06$ & $2.54 \mathrm{E}+06$ & $50 S$ ribosomal protein L10 & Protein synthesis \\
\hline sll1743 & $3.56 \mathrm{E}+05$ & $5.73 E+05$ & $6.30 \mathrm{E}+05$ & $3.00 \mathrm{E}+05$ & $3.86 \mathrm{E}+05$ & $4.17 \mathrm{E}+05$ & $2.23 E+05$ & $4.90 E+05$ & $4.11 \mathrm{E}+05$ & $50 S$ ribosomal protein L11 & Protein synthesis \\
\hline sll1746 & $6.76 \mathrm{E}+05$ & $5.38 \mathrm{E}+05$ & $7.26 \mathrm{E}+05$ & $1.66 \mathrm{E}+05$ & $2.49 E+05$ & $2.90 E+05$ & $1.78 \mathrm{E}+05$ & $2.78 \mathrm{E}+05$ & $2.58 \mathrm{E}+05$ & 50 S ribosomal protein L12 & Protein synthesis \\
\hline sll0767 & 2.07E+06 & $9.55 E+05$ & $2.40 \mathrm{E}+06$ & $9.92 \mathrm{E}+05$ & $9.52 \mathrm{E}+05$ & $7.76 \mathrm{E}+05$ & $6.25 E+05$ & 7.37E+05 & $6.30 \mathrm{E}+05$ & $50 S$ ribosomal protein L20 & Protein synthesis \\
\hline sll1801 & $3.47 \mathrm{E}+05$ & $5.18 \mathrm{E}+05$ & $7.09 E+05$ & $1.62 \mathrm{E}+05$ & $2.61 \mathrm{E}+05$ & 4.74E+05 & $2.32 \mathrm{E}+05$ & $5.43 \mathrm{E}+05$ & $5.32 \mathrm{E}+05$ & $50 S$ ribosomal protein L23 & Protein synthesis \\
\hline s/l1807 & $4.12 \mathrm{E}+05$ & $6.41 \mathrm{E}+05$ & $9.77 \mathrm{E}+05$ & $1.72 \mathrm{E}+05$ & $3.12 \mathrm{E}+05$ & $5.68 \mathrm{E}+05$ & $2.51 \mathrm{E}+05$ & $6.14 \mathrm{E}+05$ & $5.94 \mathrm{E}+05$ & $50 S$ ribosomal protein L24 & Protein synthesis \\
\hline ss/1426 & $5.89 \mathrm{E}+06$ & $2.35 E+06$ & $5.49 \mathrm{E}+06$ & $4.31 \mathrm{E}+06$ & $4.18 \mathrm{E}+06$ & $2.74 \mathrm{E}+06$ & $2.30 \mathrm{E}+06$ & $2.22 \mathrm{E}+06$ & $2.17 \mathrm{E}+06$ & $50 S$ ribosomal protein L35 & Protein synthesis \\
\hline$s / r 2067$ & $1.00 E+06$ & $2.39 \mathrm{E}+06$ & 4.47E+06 & $3.52 E+05$ & $1.16 \mathrm{E}+06$ & $2.61 \mathrm{E}+06$ & $8.80 E+05$ & $3.28 \mathrm{E}+06$ & $3.45 E+06$ & Allophycocyanin alpha subunit & Energy metabolism \\
\hline slr1986 & $8.68 \mathrm{E}+05$ & $1.50 \mathrm{E}+06$ & $2.98 \mathrm{E}+06$ & $2.53 \mathrm{E}+05$ & $6.79 \mathrm{E}+05$ & $1.35 E+06$ & 4.90E+05 & $1.72 \mathrm{E}+06$ & $1.75 \mathrm{E}+06$ & Allophycocyanin beta subunit & Energy metabolism \\
\hline$s / r 1198$ & $1.72 \mathrm{E}+06$ & $1.22 \mathrm{E}+06$ & $1.77 \mathrm{E}+06$ & $1.08 \mathrm{E}+06$ & $1.33 \mathrm{E}+06$ & $1.10 E+06$ & $7.41 \mathrm{E}+05$ & $1.08 \mathrm{E}+06$ & $1.12 \mathrm{E}+06$ & Ant ioxidant protein & Unclassified \\
\hline sll1322 & $2.11 \mathrm{E}+05$ & $6.36 \mathrm{E}+05$ & $8.15 \mathrm{E}+05$ & $1.31 \mathrm{E}+05$ & $4.50 \mathrm{E}+05$ & $6.64 \mathrm{E}+05$ & $3.23 \mathrm{E}+05$ & $9.71 \mathrm{E}+05$ & $7.65 \mathrm{E}+05$ & ATP synthase A chain of $\mathrm{CF}(0)$ & Energy metabolism \\
\hline ss/2615 & 4.95E+05 & $1.22 \mathrm{E}+06$ & $2.06 \mathrm{E}+06$ & $2.69 \mathrm{E}+05$ & $7.74 \mathrm{E}+05$ & $1.33 \mathrm{E}+06$ & $5.88 \mathrm{E}+05$ & $1.82 \mathrm{E}+06$ & $1.57 \mathrm{E}+06$ & ATP synthase $C$ chain of $C F(0)$ & Energy metabolism \\
\hline sll1323 & $2.28 \mathrm{E}+05$ & $5.71 E+05$ & $8.68 \mathrm{E}+05$ & $1.17 \mathrm{E}+05$ & $3.22 \mathrm{E}+05$ & $6.10 E+05$ & $2.82 E+05$ & $8.06 \mathrm{E}+05$ & $6.33 \mathrm{E}+05$ & ATP synthase subunit b' of $C F(0)$ & Energy metabolism \\
\hline sll1099 & $4.39 \mathrm{E}+05$ & $9.53 \mathrm{E}+05$ & $1.51 \mathrm{E}+06$ & $1.94 \mathrm{E}+05$ & 4.07E+05 & $7.88 \mathrm{E}+05$ & $3.36 \mathrm{E}+05$ & $9.11 \mathrm{E}+05$ & $8.63 \mathrm{E}+05$ & Elongation factor Tu & Protein synthesis \\
\hline ss 10020 & $2.52 \mathrm{E}+06$ & $6.33 E+05$ & $7.00 \mathrm{E}+05$ & $6.84 \mathrm{E}+05$ & $7.65 E+05$ & $8.17 \mathrm{E}+05$ & $7.10 E+05$ & $8.75 E+05$ & $7.41 \mathrm{E}+05$ & $\begin{array}{l}\text { Ferredoxin I, essential } \\
\text { for growth }\end{array}$ & Energy metabolism \\
\hline sll0018 & $1.97 \mathrm{E}+05$ & $7.10 \mathrm{E}+05$ & $1.21 \mathrm{E}+06$ & $1.36 \mathrm{E}+05$ & $2.37 \mathrm{E}+05$ & $7.34 \mathrm{E}+05$ & $3.61 \mathrm{E}+05$ & $1.04 \mathrm{E}+06$ & $1.08 \mathrm{E}+06$ & $\begin{array}{l}\text { Fructose-bisphosphate } \\
\text { aldolase, class II }\end{array}$ & Unclassified \\
\hline ss 10483 & $1.48 \mathrm{E}+06$ & $5.07 \mathrm{E}+05$ & $6.64 \mathrm{E}+05$ & $6.22 \mathrm{E}+05$ & $7.23 \mathrm{E}+05$ & $6.12 \mathrm{E}+05$ & $5.26 \mathrm{E}+05$ & $6.88 \mathrm{E}+05$ & $6.09 \mathrm{E}+05$ & Hypothetical protein & No Data \\
\hline slr0144 & $8.77 \mathrm{E}+05$ & $5.27 \mathrm{E}+05$ & $5.68 \mathrm{E}+05$ & $3.89 \mathrm{E}+05$ & 4.55E+05 & $3.04 E+05$ & $2.59 E+05$ & $2.49 \mathrm{E}+05$ & $2.15 E+05$ & Hypothetical protein & Hypothetical proteins \\
\hline slr1470 & $6.22 \mathrm{E}+05$ & $6.04 E+05$ & $8.56 \mathrm{E}+05$ & $4.92 \mathrm{E}+05$ & $6.35 E+05$ & $6.70 \mathrm{E}+05$ & $4.85 E+05$ & $7.30 \mathrm{E}+05$ & $6.91 \mathrm{E}+05$ & Hypothetical protein & Hypothetical proteins \\
\hline slr0373 & $4.60 E+05$ & $5.51 \mathrm{E}+05$ & $1.65 \mathrm{E}+06$ & $1.51 \mathrm{E}+05$ & $3.63 \mathrm{E}+05$ & $7.25 E+05$ & $2.74 \mathrm{E}+05$ & $9.89 \mathrm{E}+05$ & $8.96 \mathrm{E}+05$ & Hypothetical protein & No Data \\
\hline slr0749 & $9.08 \mathrm{E}+05$ & $6.46 \mathrm{E}+05$ & $1.19 \mathrm{E}+06$ & $7.58 \mathrm{E}+05$ & $1.34 \mathrm{E}+06$ & $7.50 \mathrm{E}+05$ & $4.19 E+05$ & $4.46 \mathrm{E}+05$ & $4.20 \mathrm{E}+05$ & $\begin{array}{l}\text { Light-independent protochlorophyllide } \\
\text { reductase ironprotein subunit ChIL }\end{array}$ & Cofactor biosynthesis \\
\hline slr0749 & $9.08 \mathrm{E}+05$ & $6.46 \mathrm{E}+05$ & $1.19 \mathrm{E}+06$ & $7.58 \mathrm{E}+05$ & $1.34 E+06$ & $7.50 E+05$ & $4.19 \mathrm{E}+05$ & $4.46 \mathrm{E}+05$ & $4.20 \mathrm{E}+05$ & $\begin{array}{l}\text { Light-independent protochlorophyllide } \\
\text { reductase iron protein subunit ChIL }\end{array}$ & Energy metabolism \\
\hline sll1342 & $3.21 \mathrm{E}+05$ & $5.41 \mathrm{E}+05$ & $7.43 \mathrm{E}+05$ & $2.32 \mathrm{E}+05$ & $3.29 E+05$ & $4.17 \mathrm{E}+05$ & $2.38 \mathrm{E}+05$ & 4.80E+05 & $5.42 \mathrm{E}+05$ & $\begin{array}{l}\text { NAD(P)-dependent glyceraldehyde- } \\
\text { 3-phosphate dehydrogenase }\end{array}$ & Energy metabolism \\
\hline slr1834 & $1.46 \mathrm{E}+06$ & $1.55 E+07$ & $3.92 \mathrm{E}+07$ & $1.23 E+06$ & $5.28 \mathrm{E}+06$ & $1.28 \mathrm{E}+07$ & $3.37 E+06$ & $1.50 \mathrm{E}+07$ & $1.66 \mathrm{E}+07$ & P700 apoprotein subunit la & Energy metabolism \\
\hline $\operatorname{slr} 1835$ & $1.21 \mathrm{E}+06$ & $5.21 \mathrm{E}+06$ & $1.16 \mathrm{E}+07$ & $6.51 \mathrm{E}+05$ & $2.62 E+06$ & $5.15 E+06$ & $1.74 \mathrm{E}+06$ & $5.93 \mathrm{E}+06$ & $5.79 \mathrm{E}+06$ & P700 apoprotein subunit Ib & Energy metabolism \\
\hline sll0819 & $1.20 \mathrm{E}+06$ & $6.37 \mathrm{E}+05$ & $6.10 E+05$ & $3.32 \mathrm{E}+05$ & $2.99 E+05$ & $3.72 \mathrm{E}+05$ & $2.59 E+05$ & $4.10 E+05$ & $3.91 \mathrm{E}+05$ & $\begin{array}{l}\text { Photosystem I reaction center } \\
\text { subunit III precursor }\end{array}$ & Energy metabolism \\
\hline slr0737 & $1.85 \mathrm{E}+06$ & $1.15 E+06$ & $2.11 \mathrm{E}+06$ & $9.16 \mathrm{E}+05$ & $1.10 \mathrm{E}+06$ & $1.20 \mathrm{E}+06$ & $8.97 \mathrm{E}+05$ & $1.34 \mathrm{E}+06$ & $1.38 \mathrm{E}+06$ & Photosystem I subunit I| & Energy metabolism \\
\hline
\end{tabular}

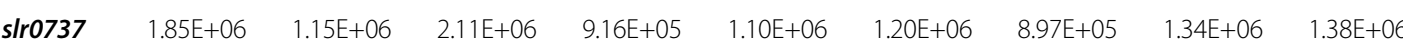


Table $\mathbf{2}$ Top $\mathbf{5 0}$ expressed genes based on normalized expression level (RPKM values) (Continued)

\begin{tabular}{|c|c|c|c|c|c|c|c|c|c|c|c|}
\hline smr0004 & $4.02 \mathrm{E}+06$ & $3.59 \mathrm{E}+06$ & $5.24 \mathrm{E}+06$ & $1.43 \mathrm{E}+06$ & $1.45 \mathrm{E}+06$ & $1.78 \mathrm{E}+06$ & $1.44 \mathrm{E}+06$ & $1.60 \mathrm{E}+06$ & $1.58 \mathrm{E}+06$ & Photosystem I subunit VIII & Energy metabolism \\
\hline slr1655 & $1.08 \mathrm{E}+07$ & $5.24 \mathrm{E}+06$ & $5.95 \mathrm{E}+06$ & $8.83 \mathrm{E}+06$ & $8.55 \mathrm{E}+06$ & $7.79 \mathrm{E}+06$ & 5.87E+06 & $7.50 \mathrm{E}+06$ & $6.75 E+06$ & Photosystem I subunit XI & Energy metabolism \\
\hline slr0906 & $2.96 \mathrm{E}+05$ & $5.56 \mathrm{E}+05$ & $4.91 \mathrm{E}+05$ & $1.78 \mathrm{E}+05$ & $4.12 \mathrm{E}+05$ & $5.30 \mathrm{E}+05$ & $2.60 \mathrm{E}+05$ & $7.12 \mathrm{E}+05$ & $6.19 \mathrm{E}+05$ & Photosystem II core light harvest ing protein & Energy metabolism \\
\hline sll0851 & $2.98 \mathrm{E}+05$ & $1.21 \mathrm{E}+06$ & $2.33 \mathrm{E}+06$ & $1.71 \mathrm{E}+05$ & $4.95 E+05$ & $1.05 \mathrm{E}+06$ & $3.40 \mathrm{E}+05$ & $9.30 \mathrm{E}+05$ & $9.78 \mathrm{E}+05$ & Photosystem II CP43 protein & Energy metabolism \\
\hline slr1311 & $2.37 \mathrm{E}+06$ & $1.75 \mathrm{E}+06$ & $2.79 \mathrm{E}+06$ & $8.49 \mathrm{E}+05$ & $1.83 \mathrm{E}+06$ & $2.41 \mathrm{E}+06$ & $1.39 \mathrm{E}+06$ & $2.73 \mathrm{E}+06$ & $2.44 \mathrm{E}+06$ & Photosystem II D1 protein & Energy metabolism \\
\hline sll1867 & $1.22 \mathrm{E}+06$ & $1.06 \mathrm{E}+06$ & $1.62 \mathrm{E}+06$ & $5.25 E+05$ & $1.01 \mathrm{E}+06$ & $1.33 \mathrm{E}+06$ & $7.68 \mathrm{E}+05$ & $1.54 \mathrm{E}+06$ & $1.59 \mathrm{E}+06$ & Photosystem II D1 protein & Energy metabolism \\
\hline sll0849 & $1.31 \mathrm{E}+05$ & $1.09 \mathrm{E}+06$ & $1.59 \mathrm{E}+06$ & $9.21 \mathrm{E}+04$ & $3.93 \mathrm{E}+05$ & $1.05 \mathrm{E}+06$ & $3.10 \mathrm{E}+05$ & $1.21 \mathrm{E}+06$ & $1.20 \mathrm{E}+06$ & $\begin{array}{l}\text { Photosystem II react ion center } \\
\text { D2 protein }\end{array}$ & Energy metabolism \\
\hline slr0335 & $4.12 \mathrm{E}+05$ & $1.38 \mathrm{E}+06$ & $2.12 \mathrm{E}+06$ & $2.41 \mathrm{E}+05$ & $6.30 \mathrm{E}+05$ & $1.09 \mathrm{E}+06$ & $5.13 \mathrm{E}+05$ & $1.30 \mathrm{E}+06$ & $1.35 E+06$ & $\begin{array}{l}\text { Phycobilisome core-membrane } \\
\text { linker polypept ide }\end{array}$ & Energy metabolism \\
\hline sll1580 & $3.09 \mathrm{E}+06$ & $2.89 \mathrm{E}+06$ & $2.91 \mathrm{E}+06$ & $1.93 \mathrm{E}+06$ & $2.24 \mathrm{E}+06$ & $2.18 \mathrm{E}+06$ & $1.69 \mathrm{E}+06$ & $2.23 \mathrm{E}+06$ & $1.79 \mathrm{E}+06$ & $\begin{array}{l}\text { Phycobilisome rod linker } \\
\text { polypept ide }\end{array}$ & Energy metabolism \\
\hline sll1579 & $2.30 \mathrm{E}+06$ & $2.95 \mathrm{E}+06$ & $3.31 \mathrm{E}+06$ & $1.33 \mathrm{E}+06$ & $2.07 E+06$ & $2.16 \mathrm{E}+06$ & $1.46 \mathrm{E}+06$ & $2.54 \mathrm{E}+06$ & $2.09 \mathrm{E}+06$ & Phycobilisome rod linker polypept ide & Unclassified \\
\hline$s / r 2051$ & $1.44 \mathrm{E}+06$ & $6.37 \mathrm{E}+05$ & 7.37E+05 & 4.63E+05 & $5.46 \mathrm{E}+05$ & $6.26 \mathrm{E}+05$ & $5.26 \mathrm{E}+05$ & $6.77 \mathrm{E}+05$ & $6.51 \mathrm{E}+05$ & $\begin{array}{l}\text { Phycobilisome rod-core linker } \\
\text { polypeptide }\end{array}$ & Energy metabolism \\
\hline ss/3093 & $2.10 \mathrm{E}+06$ & $1.29 \mathrm{E}+06$ & $1.36 \mathrm{E}+06$ & $7.71 \mathrm{E}+05$ & $9.40 \mathrm{E}+05$ & $8.59 \mathrm{E}+05$ & $7.79 \mathrm{E}+05$ & $1.04 \mathrm{E}+06$ & $7.32 \mathrm{E}+05$ & $\begin{array}{l}\text { Phycobilisome small rod linker } \\
\text { polypeptide }\end{array}$ & Unclassified \\
\hline sll1578 & $2.59 \mathrm{E}+07$ & $5.16 \mathrm{E}+07$ & $8.62 \mathrm{E}+07$ & $1.43 \mathrm{E}+07$ & $2.65 \mathrm{E}+07$ & $4.10 \mathrm{E}+07$ & $2.17 \mathrm{E}+07$ & $5.20 \mathrm{E}+07$ & $5.40 \mathrm{E}+07$ & Phycocyanin alpha subunit & Energy metabolism \\
\hline sl1577 & $2.49 \mathrm{E}+07$ & $5.74 \mathrm{E}+07$ & $8.88 \mathrm{E}+07$ & $1.88 \mathrm{E}+07$ & $3.58 \mathrm{E}+07$ & $5.52 \mathrm{E}+07$ & $2.70 \mathrm{E}+07$ & $7.35 \mathrm{E}+07$ & $7.72 \mathrm{E}+07$ & Phycocyanin beta subunit & Energy metabolism \\
\hline sll1694 & $5.95 \mathrm{E}+06$ & $8.44 \mathrm{E}+05$ & $1.14 \mathrm{E}+06$ & $2.01 \mathrm{E}+06$ & $2.12 \mathrm{E}+06$ & $9.58 \mathrm{E}+05$ & $1.35 E+06$ & $1.07 \mathrm{E}+06$ & $5.81 \mathrm{E}+05$ & Pilin polypept ide PilA1 & Cell envelope \\
\hline sllo199 & $8.92 \mathrm{E}+05$ & $6.80 \mathrm{E}+05$ & $9.96 \mathrm{E}+05$ & $2.02 \mathrm{E}+05$ & $5.59 \mathrm{E}+05$ & $9.24 \mathrm{E}+05$ & $4.93 \mathrm{E}+05$ & $8.49 \mathrm{E}+05$ & $7.72 \mathrm{E}+05$ & Plastocyanin & Unclassified \\
\hline slr0011 & $1.94 \mathrm{E}+06$ & $3.06 \mathrm{E}+06$ & $6.38 \mathrm{E}+06$ & $1.11 \mathrm{E}+06$ & $1.85 \mathrm{E}+06$ & $2.48 \mathrm{E}+06$ & $1.33 \mathrm{E}+06$ & $2.73 E+06$ & $2.32 \mathrm{E}+06$ & Possible Rubisco chaperonin & Hypothetical proteins \\
\hline slr1841 & $1.24 \mathrm{E}+06$ & $2.09 E+06$ & $3.27 \mathrm{E}+06$ & $5.53 \mathrm{E}+05$ & $1.31 E+06$ & $1.70 E+06$ & $7.51 E+05$ & $1.67 E+06$ & $1.89 \mathrm{E}+06$ & $\begin{array}{l}\text { Probable porin; major outer } \\
\text { membrane protein }\end{array}$ & Unclassified \\
\hline slr0009 & $4.48 \mathrm{E}+05$ & $1.44 \mathrm{E}+06$ & $2.53 \mathrm{E}+06$ & $2.81 \mathrm{E}+05$ & $7.69 \mathrm{E}+05$ & $1.33 \mathrm{E}+06$ & $5.61 \mathrm{E}+05$ & $1.70 \mathrm{E}+06$ & $1.55 E+06$ & $\begin{array}{l}\text { Ribulose bisphosphate carboxylase } \\
\text { large subunit }\end{array}$ & Energy metabolism \\
\hline slr0012 & $5.54 \mathrm{E}+05$ & $8.40 \mathrm{E}+05$ & $2.10 \mathrm{E}+06$ & $1.58 \mathrm{E}+05$ & $2.52 \mathrm{E}+05$ & $4.06 \mathrm{E}+05$ & $2.72 \mathrm{E}+05$ & $4.43 E+05$ & $3.79 \mathrm{E}+05$ & $\begin{array}{l}\text { Ribulose bisphosphate carboxylase } \\
\text { small subunit }\end{array}$ & Energy metabolism \\
\hline sll1338 & $9.93 \mathrm{E}+05$ & $2.56 \mathrm{E}+06$ & $4.45 \mathrm{E}+06$ & $5.64 E+05$ & $1.23 E+06$ & $1.57 \mathrm{E}+06$ & $9.14 \mathrm{E}+05$ & $1.79 \mathrm{E}+06$ & $1.52 \mathrm{E}+06$ & Unknown protein & No Data \\
\hline sll1951 & $7.54 \mathrm{E}+05$ & 8.37E+05 & $1.25 E+06$ & $3.14 \mathrm{E}+05$ & $6.19 E+05$ & $7.53 \mathrm{E}+05$ & $3.27 \mathrm{E}+05$ & $7.44 \mathrm{E}+05$ & $8.16 \mathrm{E}+05$ & Unknown protein & Unclassified \\
\hline
\end{tabular}




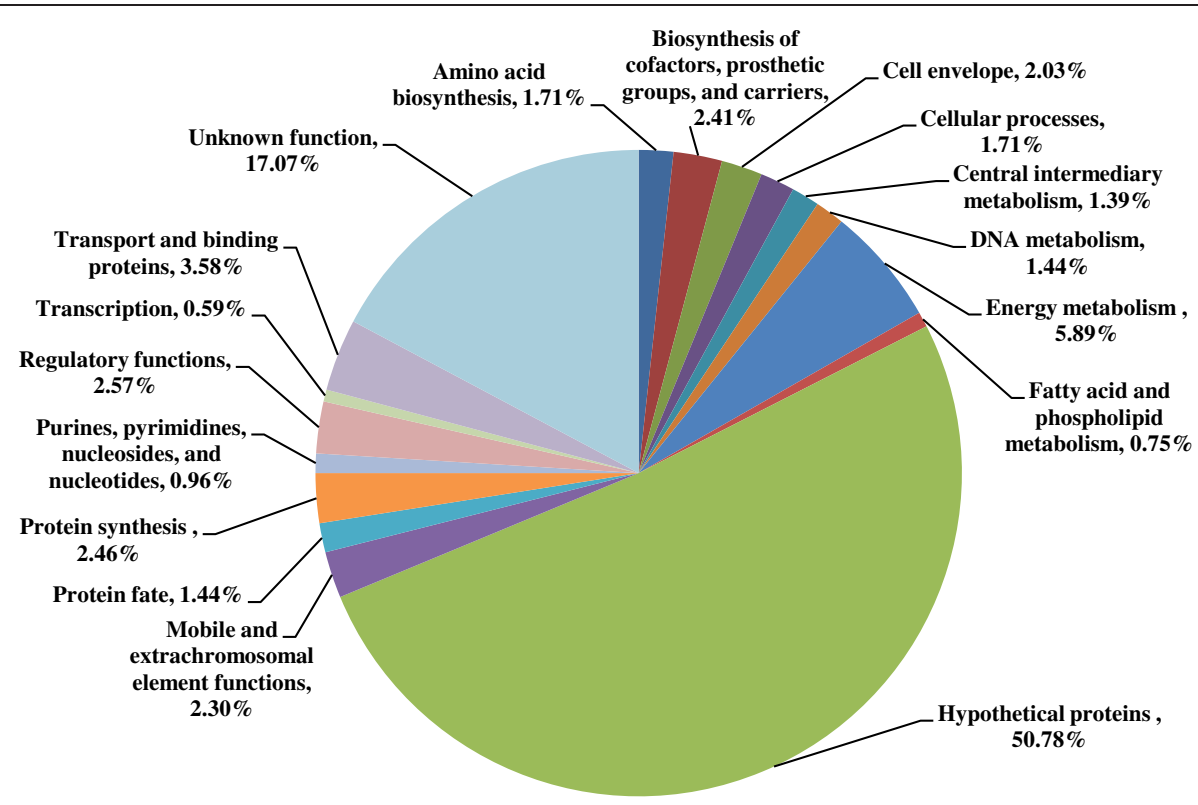

Figure 2 Pie chart of down-regulated genes by functional categories.

genome is still annotated as hypothetical up to now $[10,18]$. Other most affected functional categories included "Energy metabolism", "Protein synthesis" and "Regulatory functions". Down-regulation of the central metabolism is consistent with the overall slower growth upon ethanol stress [9]. For the up-regulated genes, 29, 114 and 161 genes were up-regulated at $24 \mathrm{~h}, 48 \mathrm{~h}$ and $72 \mathrm{~h}$, respectively, among which 3 genes were upregulated in all three time points (Table 3 and Additional file 3: Table S3). More genes up-regulated at late growth phases suggested that cells needed time to adjust their metabolism and initiate resistance responses.

\section{Correlation with quantitative RT-PCR analysis}

Based on their expression level and regulation patterns by ethanol, a subset of 12 genes was selected for quantitative RT-PCR validation. Among them, six genes were down-regulated (i.e. sll0721, sll1796, slr1992, sll0248, sll1327, ssr1399) and six genes were up-regulated (i.e. sll1734, slr1761, slr1828, sll1091, slr0288, sll0057) by ethanol, respectively according to the RNA-seq transcriptomics data. Under control condition, their expression levels varied from the normalized RPKM values 2529.6 for sll0248 (encoding a flavodoxin) to 421749.3 for ssr1399 (encoding ribosomal protein S18) (Additional file 4: Table S4). RT-PCR analysis was performed for the genes between the treated sample and control for all three time points (i.e. 24, 48 and 72 h). The results showed obvious positive correlation can be detected between qRT-PCR and RNA-Seq transcriptomics data (with correlation coefficient of 0.75-0.8) (Figure 3), suggesting a good quality of RNA-seq data.

\section{Cells utilize multiple approaches to cope with ethanol} stress

Our previous proteomic analysis found that the Synechocystis cells employed a combination of induced common stress response, modifications of cell membrane and envelope, and induction of multiple transporters and cell mobility-related proteins as protection mechanisms against ethanol toxicity [9]. At transcriptional level, a very similar response was also observed [9]. First, we found that common stress responses were induced: one gene encoding a heat-shock DnaK homo$\log$ (slr0086) was induced at $72 \mathrm{~h}$. Multiple genes involved in resistance against reactive oxygen species (ROS), such as slr2033 encoding a membraneassociated rubredoxin, slr1109 encoding ankyrin homo$\log$ [19], sll1545 encoding glutathione S-transferase [20], slr0242 encoding a bacterioferritin comigratory protein [21] and slr1379 encoding quinol oxidase subunit I [22] were up-regulated. In addition, consistent with findings from proteomic analysis, we found circadian rhythms of Synechocystis sp. PCC 6803 was also regulated by ethanol. It was reported that cyanobacterial circadian rhythms are controlled by a cluster of three genes, kaiA, kaiB, and kaiC [23]. Previous proteomic analysis showed that one of the key circadian clock proteins, KaiB (Slr0757), was induced [9]. RNASeq transcriptomic analysis showed that kaiC gene (slr0758) was also induced (Table 3). Transcripomics analysis here complemented well with the proteomic analysis, further confirming that circadian rhythms are induced by ethanol treatment. The ethanol-induced genes were listed in Table 3, while the induced genes 
Table 3 Genes induced by ethanol exposure *

\begin{tabular}{|c|c|c|c|c|c|c|c|}
\hline Gene ID & Description & $\begin{array}{c}\text { Ratio- } \\
\text { Ethanol- } \\
24 \mathrm{~h}-\mathrm{r} 1 \text { vs. } \\
\text { Control-24h }\end{array}$ & $\begin{array}{c}\text { Ratio-Ethanol- } \\
24 \mathrm{~h}-\mathrm{r} 2 \text { vs. } \\
\text { Control-24h }\end{array}$ & $\begin{array}{c}\text { Ratio-Ethanol- } \\
48 \mathrm{~h}-\mathrm{r} 1 \mathrm{vs.} \\
\text { Control-48h }\end{array}$ & $\begin{array}{c}\text { Ethanol- } \\
48 \mathrm{~h}-\mathrm{r} 2 \text { vs. } \\
\text { Control-48h }\end{array}$ & $\begin{array}{l}\text { Ethanol- } \\
\text { 72h-r1 vs. } \\
\text { Control-72h }\end{array}$ & $\begin{array}{l}\text { Ratio-Ethanol- } \\
72 \mathrm{~h}-\mathrm{r} 1 \text { vs. } \\
\text { Control-72h }\end{array}$ \\
\hline sll0034 & putative carboxypeptidase & & & 2.69 & 1.50 & & \\
\hline sll0250 & $\begin{array}{l}\text { pantothenate metabolism } \\
\text { flavoprotein }\end{array}$ & & & & & 3.00 & 1.91 \\
\hline sll0289 & $\begin{array}{l}\text { septum site-determining } \\
\text { protein MinD }\end{array}$ & & & & & 4.56 & 3.89 \\
\hline sll0300 & $\begin{array}{l}\text { riboflavin synthase alpha } \\
\text { chain }\end{array}$ & & & & & 4.33 & 3.33 \\
\hline sll0330 & sepiapterine reductase & & & & & 7.09 & 29.09 \\
\hline sll0368 & uracil phosphoribosyltransferase & & & & & 2.33 & 2.00 \\
\hline sll0374 & $\begin{array}{l}\text { urea transport system } \\
\text { ATP-binding protein }\end{array}$ & & & 2.80 & 3.60 & & \\
\hline sll0384 & Cations and iron carrying protein & & & 2.31 & 1.70 & & \\
\hline sll0450 & $\begin{array}{l}\text { cytochrome } b \text { subunit of nitric } \\
\text { oxide reductase }\end{array}$ & 1.62 & 4.26 & & & & \\
\hline sll0536 & $\begin{array}{l}\text { probable potassium channel } \\
\text { protein }\end{array}$ & & & 2.00 & 1.93 & & \\
\hline sll0540 & $\begin{array}{l}\text { phosphate-binding protein } \\
\text { PstS homolog }\end{array}$ & & & & & 1.57 & 1.79 \\
\hline sll0613 & $\begin{array}{l}\text { Holliday junction DNA helicase } \\
\text { RuvB }\end{array}$ & & & 1.73 & 1.91 & & \\
\hline sll0621 & $\begin{array}{c}\text { putative c-type cytochrome biogenesis } \\
\text { protein CcdA }\end{array}$ & & & & & 2.22 & 2.00 \\
\hline sll0629 & $\begin{array}{l}\text { alternative photosystem I reaction } \\
\text { center subunit } X\end{array}$ & & & 1.94 & 1.72 & & \\
\hline sll0671 & probable cation transporter & 4.00 & 4.00 & & & & \\
\hline sll0686 & $\begin{array}{c}\text { probable cytochrome c-type } \\
\text { biogenesis protein }\end{array}$ & & & & & 3.00 & 3.25 \\
\hline sll0687 & $\begin{array}{l}\text { RNA polymerase ECF-type (group 3) } \\
\text { sigma factor }\end{array}$ & & & 3.00 & 6.00 & & \\
\hline sll0759 & $\begin{array}{c}\text { ABC transporter ATP-binding } \\
\text { protein }\end{array}$ & & & & & 2.13 & 2.09 \\
\hline sll0759 & $\begin{array}{c}\text { ABC transporter ATP-binding } \\
\text { protein }\end{array}$ & & & & & 2.13 & 2.09 \\
\hline sll0792 & Zinc-responsive repressor ZiaR & & & 3.43 & 3.00 & & \\
\hline sll0856 & $\begin{array}{l}\text { RNA polymerase ECF-type (group 3) } \\
\text { sigma-E factor }\end{array}$ & & & & & 1.89 & 1.61 \\
\hline sll1041 & $\begin{array}{l}\text { similar to sulfate transport } \\
\text { ATP-binding protein CysA }\end{array}$ & & & 2.63 & 1.63 & & \\
\hline sll1051 & $\begin{array}{l}\text { phycocyanin alpha-subunit } \\
\text { phycocyanobilin lyase }\end{array}$ & & & & & 8.00 & 13.00 \\
\hline sll1051 & $\begin{array}{l}\text { phycocyanin alpha-subunit } \\
\text { phycocyanobilin lyase }\end{array}$ & & & & & 8.00 & 13.00 \\
\hline sll1170 & unknown protein & & & & & 2.25 & 1.50 \\
\hline sll1223 & $\begin{array}{l}\text { diaphorase subunit of the } \\
\text { bidirectional hydrogenase }\end{array}$ & 1.55 & 2.18 & & & & \\
\hline s/l1226 & $\begin{array}{l}\text { hydrogenase subunit of the } \\
\text { bidirectional hydrogenase }\end{array}$ & & & & & 1.55 & 1.89 \\
\hline sll1316 & $\begin{array}{l}\text { cytochrome b6-f complex } \\
\text { iron-sulfur subunit }\end{array}$ & & & & & 1.69 & 1.56 \\
\hline
\end{tabular}


Table 3 Genes induced by ethanol exposure * (Continued)

\begin{tabular}{|c|c|c|c|c|c|c|c|}
\hline$s / 11330$ & $\begin{array}{l}\text { two-component system response } \\
\text { regulator OmpR subfamily }\end{array}$ & & & 2.47 & 2.33 & & \\
\hline$s / 11370$ & mannose-1-phosphate guanylyltransferase & & & & & 3.25 & 1.88 \\
\hline s/l1423 & global nitrogen regulator & & & 1.57 & 1.55 & & \\
\hline s/l1428 & probable sodium-dependent transporter & 7.00 & 6.00 & & & 5.00 & 2.00 \\
\hline$s / 11440$ & pyridoxamine 5'-phosphate oxidase & & & & & 3.00 & 1.50 \\
\hline$s / 1471$ & phycobilisome rod-core linker polypeptide & 3.90 & 2.77 & 3.56 & 3.07 & & \\
\hline$s / 1473$ & $\begin{array}{c}\text { a part of phytochrome-like sensor histidine } \\
\text { kinase gene }\end{array}$ & & & 1.59 & 1.79 & & \\
\hline s/l1483 & periplasmic protein & & & & & 2.00 & 8.40 \\
\hline s/11545 & glutathione S-transferase & & & 2.00 & 1.60 & & \\
\hline s/1612 & folylpolyglutamate synthase & 2.00 & 2.67 & & & & \\
\hline$s / 11679$ & periplasmic protease HhoA & 3.35 & 2.42 & & & & \\
\hline s/11682 & alanine dehydrogenase & & & & & 2.91 & 2.27 \\
\hline s/11723 & probable glycosyltransferase & & & & & 1.53 & 4.80 \\
\hline s/11724 & probable glycosyltransferase & & & & & 2.11 & 4.89 \\
\hline s/l1994 & $\begin{array}{l}\text { porphobilinogen synthase (5- } \\
\text { aminolevulinate dehydratase) }\end{array}$ & & & & & 1.97 & 1.83 \\
\hline s/l1998 & $\begin{array}{l}\text { putative transposase [ISY100d: 1623697- } \\
1624643]\end{array}$ & & & & & 1.67 & 4.00 \\
\hline slr0018 & fumarase & & & & & 2.27 & 1.67 \\
\hline slro051 & periplasmic beta-type carbonic anhydrase & & & 1.55 & 1.60 & & \\
\hline slr0070 & methionyl-tRNA formyltransferase & & & & & 1.62 & 1.69 \\
\hline slr0086 & similar to Dnak protein & & & & & 1.50 & 2.50 \\
\hline slr0089 & gamma-tocopherol methyltransferase & & & & & 4.60 & 3.80 \\
\hline slr0091 & aldehyde dehydrogenase & & & & & 7.00 & 11.00 \\
\hline slr0242 & $\begin{array}{l}\text { bacterioferritin comigratory protein } \\
\text { homolog }\end{array}$ & & & 1.58 & 1.65 & & \\
\hline slr0328 & $\begin{array}{l}\text { low molecular weight phosphotyrosine } \\
\text { protein phosphatase }\end{array}$ & & & & & 2.75 & 2.00 \\
\hline slr0381 & lactoylglutathione lyase & & & & & 5.14 & 5.00 \\
\hline slr0502 & $\begin{array}{c}\text { cobalamin synthesis protein cobW } \\
\text { homolog }\end{array}$ & 1.75 & 1.88 & & & 1.83 & 1.67 \\
\hline slr0574 & cytochrome P450 & & & & & 2.34 & 2.41 \\
\hline slr0585 & argininosuccinate synthetase & & & & & 2.32 & 2.42 \\
\hline slr0618 & cobyric acid synthase & & & 1.69 & 1.56 & & \\
\hline slr0678 & biopolymer transport ExbD like protein & & & & & 2.19 & 2.26 \\
\hline slr0721 & malic enzyme & & & & & 1.67 & 2.29 \\
\hline slr0724 & HtaR suppressor protein homolog & & & & & 2.00 & 1.50 \\
\hline slr0741 & transcriptional regulator & & & & & 2.13 & 2.63 \\
\hline slr0758 & circadian clock protein KaiC homolog & & & 2.16 & 1.52 & & \\
\hline slr0819 & apolipoprotein N-acyltransferase & & & & & 2.17 & 1.67 \\
\hline slr0898 & ferredoxin-nitrite reductase & & & 1.65 & 1.53 & & \\
\hline slr0903 & $\begin{array}{c}\text { molybdopterin (MPT) converting factor, } \\
\text { subunit } 2\end{array}$ & 3.00 & 2.50 & & & & \\
\hline slro940 & zeta-carotene desaturase & & & 1.87 & 2.00 & 2.03 & 1.70 \\
\hline slro942 & alcohol dehydrogenase [NADP+] & & & 1.76 & 1.58 & & \\
\hline
\end{tabular}


Table 3 Genes induced by ethanol exposure * (Continued)

\begin{tabular}{|c|c|c|c|c|c|c|c|}
\hline slr0946 & arsenate reductase & & & & & 4.50 & 3.50 \\
\hline slr0947 & $\begin{array}{l}\text { response regulator for energy transfer from } \\
\text { phycobilisomes to photosystems }\end{array}$ & & & & & 2.56 & 1.74 \\
\hline slro949 & $\begin{array}{l}\text { Integral membrane protein of the } A B C- \\
\text { type Nat permease NatD }\end{array}$ & & & & & 14.00 & 7.00 \\
\hline slr1093 & $\begin{array}{l}\text { 2-amino-4-hydroxy-6- } \\
\text { hydroxymethyldihydropteridine } \\
\text { pyrophosphokinase }\end{array}$ & & & 1.73 & 1.94 & & \\
\hline sirn109 & similar to ankyrin & & & & & 2.09 & 1.53 \\
\hline $\operatorname{sir} 1120$ & $\begin{array}{l}\text { type } 4 \text { prepilin-like proteins leader peptide } \\
\text { processing enzyme }\end{array}$ & 8.00 & 3.00 & & & & \\
\hline $\operatorname{sir} 1185$ & $\begin{array}{l}\text { cytochrome b6-f complex alternative iron- } \\
\text { sulfur subunit }\end{array}$ & & & & & 8.00 & 5.00 \\
\hline slr1197 & SMF protein & & & & & 1.73 & 1.53 \\
\hline slr1204 & protease & & & 9.52 & 1.96 & 2.45 & 6.65 \\
\hline $\operatorname{sir} 1205$ & $\begin{array}{l}\text { similar to chlorobenzene dioxygenase, } \\
\text { ferredoxin component }\end{array}$ & & & & & 4.00 & 4.00 \\
\hline $\operatorname{sir} 1225$ & serine/threonine kinase & & & & & 2.70 & 2.50 \\
\hline sir1291 & NADH dehydrogenase subunit 4 & & & & & 2.44 & 2.44 \\
\hline $\operatorname{sir} 1300$ & $\begin{array}{c}\text { similar to 2-octaprenyl-6-methoxyphenol } \\
\text { hydroxylase }\end{array}$ & & & & & 1.59 & 1.59 \\
\hline $\operatorname{sir} 1350$ & acyl-lipid desaturase & & & & & 1.72 & 1.57 \\
\hline $\operatorname{sir} 1379$ & quinol oxidase subunit I & 1.56 & 1.70 & & & & \\
\hline $\operatorname{sir} 1418$ & dihydroorotate dehydrogenase & & & & & 2.50 & 2.63 \\
\hline $\operatorname{sir} 1452$ & $\begin{array}{c}\text { sulfate transport system substrate-binding } \\
\text { protein }\end{array}$ & 1.83 & 2.00 & & & & \\
\hline slr1596 & a protein in the cytoplasmic membrane & & & & & 2.31 & 2.08 \\
\hline $\operatorname{sir} 1626$ & dihydroneopterin aldolase & & & 1.80 & 3.30 & & \\
\hline slr1805 & two-component sensor histidine kinase & & & & & 1.60 & 1.98 \\
\hline $\operatorname{sir} 1828$ & ferredoxin, petF-like protein & & & 2.00 & 2.33 & 5.50 & 9.00 \\
\hline $\operatorname{sir} 1848$ & histidinol dehydrogenase & & & & & 2.15 & 2.06 \\
\hline $\operatorname{sir} 1848$ & histidinol dehydrogenase & & & & & 2.15 & 2.06 \\
\hline $\operatorname{sir} 1853$ & carboxymuconolactone decarboxylase & 1.80 & 1.70 & 2.71 & 1.59 & 2.56 & 2.55 \\
\hline $\operatorname{sir1854}$ & unknown protein & & & 2.10 & 1.84 & 1.88 & 1.89 \\
\hline$s / r 1874$ & D-alanine-D-alanine ligase & & & 1.84 & 1.88 & & \\
\hline slr1877 & $\begin{array}{l}\text { 2-hydroxyhepta-2,4-diene-1,7-dioate } \\
\text { isomerase }\end{array}$ & & & 2.00 & 1.92 & & \\
\hline $\operatorname{sir1884}$ & tryptophanyl-tRNA synthetase & & & & & 2.09 & 1.72 \\
\hline slr1910 & $\begin{array}{l}\text { probable } \mathrm{N} \text {-acetylmuramoyl-L-alanine } \\
\text { amidase }\end{array}$ & & & & & 1.71 & 2.00 \\
\hline slr1933 & dTDP-4-dehydrorhamnose 3,5-epimerase & & & & & 3.50 & 5.50 \\
\hline $\operatorname{sir} 1938$ & $\begin{array}{l}\text { putative translation initiation factor EIF-2b } \\
\text { subunit } 1\end{array}$ & & & 2.45 & 2.00 & & \\
\hline $\operatorname{sir} 1962$ & $\begin{array}{c}\text { probable extracellular solute-binding } \\
\text { protein }\end{array}$ & & & 1.79 & 1.50 & & \\
\hline slr1993 & PHA-specific beta-ketothiolase & & & & & 1.93 & 2.00 \\
\hline slr1994 & PHA-specific acetoacetyl-CoA reductase & 6.00 & 9.00 & 5.00 & 2.00 & 2.57 & 2.29 \\
\hline slr2033 & membrane-associated rubredoxin & 1.85 & 3.38 & & & 2.23 & 1.56 \\
\hline slr2114 & perosamine synthetase & & & & & 7.00 & 6.00 \\
\hline
\end{tabular}


Table 3 Genes induced by ethanol exposure * (Continued)

\begin{tabular}{|c|c|c|c|c|c|c|c|}
\hline$s / r 2131$ & RND multidrug efflux transporter & & & & & 3.45 & 3.44 \\
\hline$s / r 2143$ & L-cysteine/cystine lyase & 1.67 & 2.56 & & & & \\
\hline smro003 & cytochrome b6-f complex subunit PetM & & & & & 2.40 & 3.40 \\
\hline smrooog & photosystem II PsbN protein & & & 1.56 & 1.78 & & \\
\hline ss 10563 & photosystem I subunit VII & & & & & 1.76 & 1.56 \\
\hline ss 10707 & nitrogen regulatory protein $\mathrm{P}-\|$ & & & 2.00 & 1.64 & & \\
\hline ss/2153 & probable ribose phosphate isomerase $B$ & & & 4.50 & 2.50 & & \\
\hline ss 12296 & pterin-4a-carbinolamine dehydratase & & & 1.75 & 1.86 & & \\
\hline ss/2542 & $\begin{array}{l}\text { high light-inducible polypeptide HliA, CAB/ } \\
\text { ELIP/HLIP superfamily }\end{array}$ & & & & & 4.00 & 5.00 \\
\hline ss/3580 & $\begin{array}{c}\text { putative hydrogenase expression/formation } \\
\text { protein HypC }\end{array}$ & & & 3.15 & 2.05 & & \\
\hline ssr1176 & putative transposase & & & 1.50 & 1.83 & & \\
\hline $\operatorname{ssr1480}$ & putative RNA-binding protein & & & 2.42 & 1.92 & & \\
\hline
\end{tabular}

* Induced genes encoding hypothetical proteins are provided in Additional file 3: Table S3.

encoding hypothetical proteins were provided in Additional file 3: Table S3.

Cross-membrane transporters for small molecules have been suggested as one important mechanism against ethanol toxicity in the early studies with yeast $[24,25]$. In cyanobacteria, transporters were also involved in tolerance to many different types of stresses, such as arsenate, $\mathrm{Cu}^{2+}$,

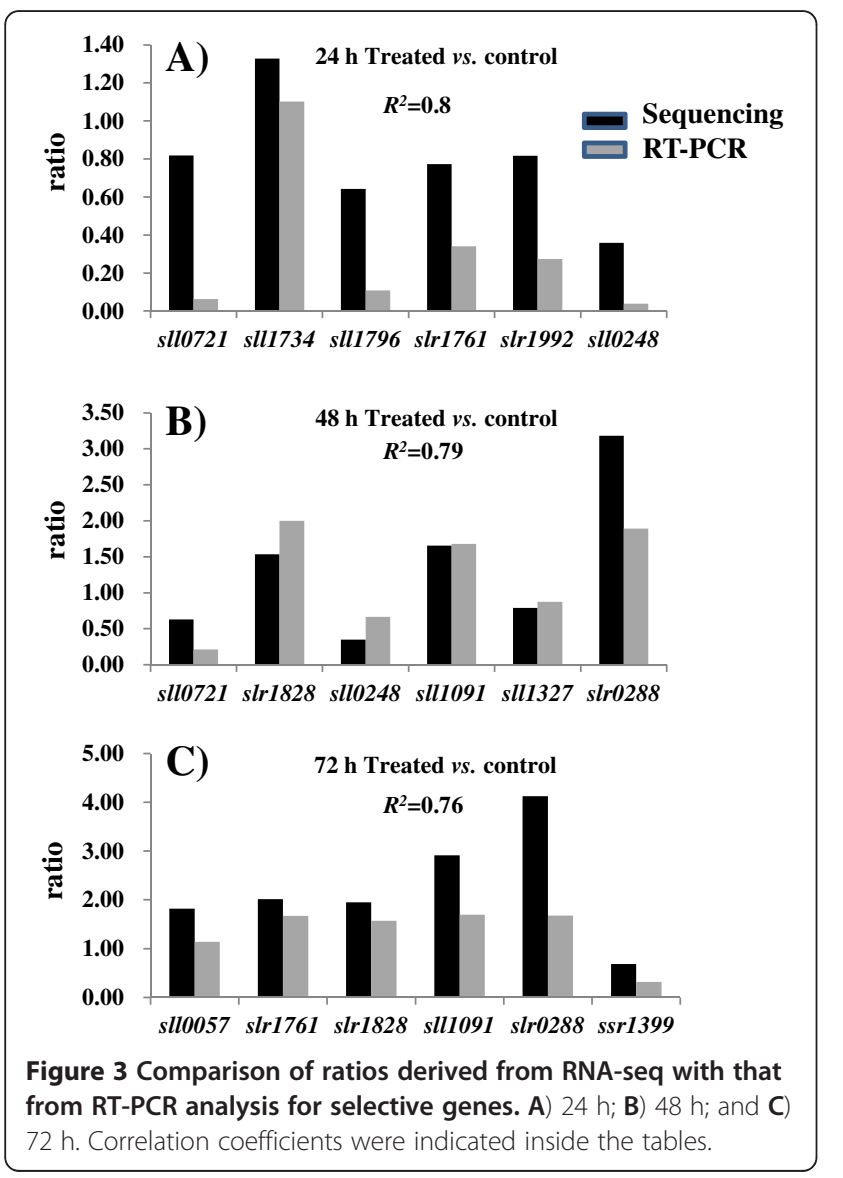

salinity and heavy metals [26-30]. Our quantitative proteomic analysis also identified 5 putative transporters with different substrate specificity induced by ethanol exposure [9]. RNA-Seq based transcriptomics found 12 transporters were induced by ethanol at varying growth phases. Similarly, these transport proteins were also with a wide range of putative functions and substrate specificity: sll0759 encoding an ABC transporter ATP-binding protein, slr0949 encoding an integral membrane protein of the ABC-type Nat permease, sll0540 encoding a phosphate-binding protein PstS homolog, sll0671 encoding a probable cation transporter, sll0536 encoding a probable potassium channel protein, sll1428 encoding a probable sodiumdependent transporter, slr2131 encoding a RND multidrug efflux transporter, sll0384 encoding a cation and iron carrying protein, sll1041 encoding a sulfate transport ATPbinding protein CysA, sll0374 encoding a urea transport system ATP-binding protein, and slr0678 encoding a biopolymer transport ExbD like protein, and slr1452 encoding a sulfate transport system substrate-binding protein. Interestingly, they represented a totally different set of ethanolinduced transporters when compared with transporters revealed by proteomics analysis [9], although they shared some similarity in terms of substrate specificity as two of previously identified transporters, Sll0689 as a sodiumdependent transporter and Slr1295 as an iron transporter.

Early studies have found that many microbes can modify their cell membrane and envelope to increase tolerance to ethanol [24,31]. One well described change is the shift from cis to trans unsaturated fatty acids to decrease membrane fluidity, resulting in a corresponding increase in solvent tolerance [8]. RNA-seq transcriptomics analysis showed that $\operatorname{sir} 1350$ encoding acyl-lipid desaturase was up-regulated at $72 \mathrm{~h}$. In a previous study, the acyl-lipid desaturase (desA) gene from Synechocystis sp. PCC6803 was expressed in prokaryotic (E. coli) and 
eukaryotic (Solanum tuberosum) cells, which led to an enhanced cold tolerance due to increased unsaturated fatty acid concentration in their lipids [32]. Several genes encoding cell envelope proteins were found induced by ethanol exposure (Table 3). The slr0819 gene encoding apolipoprotein $\mathrm{N}$-acyltransferase was induced 2.17 and 1.67 fold in both biological replicates at $72 \mathrm{~h}$. Apolipoprotein $\mathrm{N}$-acyltransferase is able to transfer an acyl group from sn-1-glycerophospholipid to the free alpha-amino group of the $\mathrm{N}$-terminal cysteine of apolipoproteins, resulting in mature triacylated lipoprotein which plays important role in bacterial survival in mice for Staphylococcus aureus [33,34]. The sll1370 gene encoding a mannose-1-phosphate guanylyltransferase was induced 3.25 and 1.88 fold in both biological replicates at $72 \mathrm{~h}$. Mannose-1-phosphate guanylyltransferase is involved in lipopolysaccharide biosynthesis which has been found necessary for adaptation to high external $\mathrm{NaCl}$ stress in Rhizobium tropici [35]. The slr1910 gene encoding a probable $\mathrm{N}$-acetylmuramoyl-Lalanine amidase was induced 1.71 and 2.00 fold in both biological replicates at $72 \mathrm{~h}$. $\mathrm{N}$-acetylmuramoyl-L-alanine amidase has been suggested involved in degradation and reconstruction of the cell peptidoglycan layer in Anabaena sp. strain PCC 7120 [36]. Up-regulation of these cell envelope proteins by ethanol exposure could contribute to strengthening cell wall and extracellular matrix for stress resistance, although the mechanism still needs more investigation.

Polyhydroxyalkanoates (PHAs) are highly reduced bacterial storage compounds that are accumulated in most bacteria during unbalanced growth conditions [37]. Accumulation and degradation of PHAs endow bacteria with enhanced survival, competition abilities, and stress tolerance, increasing fitness in changing environments $[37,38]$. RNA-seq analysis identified two genes involved in PHA biosynthesis, slr1994 encoding a PHA-specific acetoacetyl-CoA reductase and $\operatorname{slr} 1993$ encoding a PHAspecific beta-ketothiolase were up-regulated. Genetic analysis suggested that these two genes were probably located in the same operon [39]. Among them, slr1994 encoding PHA-specific acetoacetyl-CoA reductase was up-regulated significantly at all three time points (i.e. 24, 48 and $72 \mathrm{~h}$ ) with 6.0 and 9.0 fold increase in both biological replicates at $24 \mathrm{~h}$ (Table 3). Although PHA accumulation has been reported for many natural stress conditions [38], it is the first time to report that this pathway is also responsive to organic solvents and biofuels.

One factor that may affect the long-term survival of bacterial cells in a population is the level of damage incurred by macromolecules via the nonenzymatic process of glycation, which is responsible for the formation of several compounds identified as advanced glycation end products (AGEs) [40]. Many biochemical pathways produce reactive dicarbonyl intermediates, such as glyoxal and methylglyoxal (MG), which can further react with DNA, proteins, or other biomolecules to form AGEs [40]. In E. coli, it has been found that the predominant MG detoxification system consisted of glyoxalase enzyme I which coverts MG to S-lactoyl glutathione [41]. In plant, the level of MG is enhanced upon exposure to different abiotic stresses and overexpression of glyoxalase pathway genes can support survival and growth of transgenic plants under various abiotic stresses [42]. RNA-Seq analysis of the ethanol-treated cells showed that lactoylglutathione lyase (also called as glyoxalase enzyme I) was up-regulated significantly by 5.14 and 5.0 fold in both biological replicates at $72 \mathrm{~h}$, suggesting that glyoxalase pathway may play important roles in resistance to ethanol stress in Synechocystis.

In the previous proteomics analysis, we unexpectedly discovered that many proteins involved in multiple aspects of photosynthesis activity (i.e. photosystem I and II, cytochrome, ferredoxin) were up-regulated even when the cell growth was slow down. We further confirmed the results by comparatively measuring chlorophyll a concentration in cells [9]. Based on our results we proposed that ethanol treatment might enhance photosynthesis in Synechocystis to generate more ROS which will trigger oxidative stress response [9]. RNA-seq transcriptomics analysis showed very similar results, although cell growth was slow, and genes involved in energy metabolism and protein synthesis were mostly down-regulated (Figure 2 and Additional file 2: Table S2), the genes involved in photosystem I and II, light collection and electron transfer, such as ssl0563 encoding photosystem I subunit VII, smr0009 encoding photosystem II PsbN protein, sll1051 encoding phycocyanin alpha-subunit phycocyanobilin lyase, and sll1471 encoding a phycobilisome rod-core linker polypeptide, and slr1828 encoding a ferredoxin were up-regulated. Among them, sll1051 encoding phycocyanin alpha-subunit phycocyanobilin lyase was increased significantly by 8.0 and 13.0 folds in both biological replicates at $72 \mathrm{~h}$ (Table 3 ). In addition, up-regulation of multiple cytochromes, such as $\operatorname{sir} 1185$ encoding cytochrome $b 6-f$ complex alternative ironsulfur subunit, sll1316 encoding cytochrome b6- $f$ complex iron-sulfur subunit, sll0450 encoding cytochrome $b$ subunit of nitric oxide reductase, smr0003 encoding cytochrome $b 6-f$ complex subunit PetM were also upregulated. The results further confirmed this unique phenomenon of cyanobacteria under stress of biofuels.

RNA-seq transcriptomics analysis identified ten signal transduction proteins induced upon ethanol exposure, including two histidine kinases (sll1473, slr1805), two response regulators (slr0947, sll1330) of bacterial twocomponent system (TCS), one serine/threonine kinase 
(slr1225) and three transcriptional regulators (slr0741, sll0792, sll1423, ssl0707) (Table 3). sll1473 encoding a phytochrome-like sensor histidine kinase, was upregulated at $48 \mathrm{~h}$. Phytochromes are red/far-red photoreceptors that bear linear tetrapyrrole (bilin) chromophores attached to an N-terminal sensory module, and have been identified in many prokaryotes, including cyanobacteria $[43,44]$. In a study, the cikA gene of the cyanobacterium Synechococcus elongatus PCC 7942, encoding a phytochrome-related histidine kinase, was found involved in signal perception for resetting the circadian clock in response to environmental cues [45]. Although still needs more proof, the up-regulation of sll1473 gene may be consistent with the enhanced expression of $\mathrm{kaiC}$ gene (slr0758) related to circadian rhythms. slr0947 encoding a response regulator for energy transfer from phycobilisomes to photosystems was up-regulated at $72 \mathrm{~h}$ after ethanol exposure. Early study has found that RpaB response regulator (Slr0947) can bind to the upstream region of the high light (HL)-inducible genes in Synechocystis sp. PCC 6803 to cope with the potentially damaging effects of high light [46]. slr0741 encoding transcriptional regulator was upregulated at $72 \mathrm{~h}$. The gene was previously found involved in transduction of the phosphate-limitation signal in Synechocystis [47]. sll1330 encoding a twocomponent system response regulator OmpR subfamily was induced by ethanol at $48 \mathrm{~h}$. A recent study found that expression of sll1330 can be enhanced by nitrogen depletion under the control of NtcA, which then activates transcript accumulation of sugar catabolic genes during nitrogen starvation [48]. slr1805 encoding a twocomponent sensor histidine kinase was up-regulated, which was previous found participating in the perception and transduction of salt-stress and hyperosmoticstress signals [49].

Considering many signal transduction genes were involved in the ethanol induced responses, we speculated that some of the ethanol-responsive genes may be under direct control of the response regulators or transcriptional regulators. To seek evidence to this hypothesis, we performed a promoter DNA-binding motif searching using 500 bp sequences extracted from upstream region of all the up-regulated genes using the Gibbs Motif Sampler software [50,51]. This analysis showed that the top conversed motifs identified were two palindrome containing 16 and 17 total sites with the DNA sequence "AXXCCTGGCCAAGGXXT" and “AAXXTTTXXAAAXXTT", respectively (Figure 4) [52]. Both motif models have several conserved positions with information bits greater than 0.5 and are highly likely to be significant [50]. The genes associated with the first motif included slr0086 encoding a DnaK protein and slr0942 encoding an alcohol dehydrogenase [NADP ${ }^{+}$] which have been confirmed in ethanol resistance in Clostridium [53] and sll1330 encoding a OmpR subfamily response regulator which was shown Sll1330 to control the expression of glycolytic genes in Synechocystis sp. PCC 6803 [54]. The genes associated with the second motif included slr1109 encoding an ankyrin, slr1828 encoding a ferredoxin, slr1994 encoding a PHAspecific acetoacetyl-CoA reductase, slr2033 encoding a membrane-associated rubredoxin and slr0940 encoding a zeta-carotene desaturase, which were all involved in stress response in various microbes. Functions of these motifs may worth further investigation.
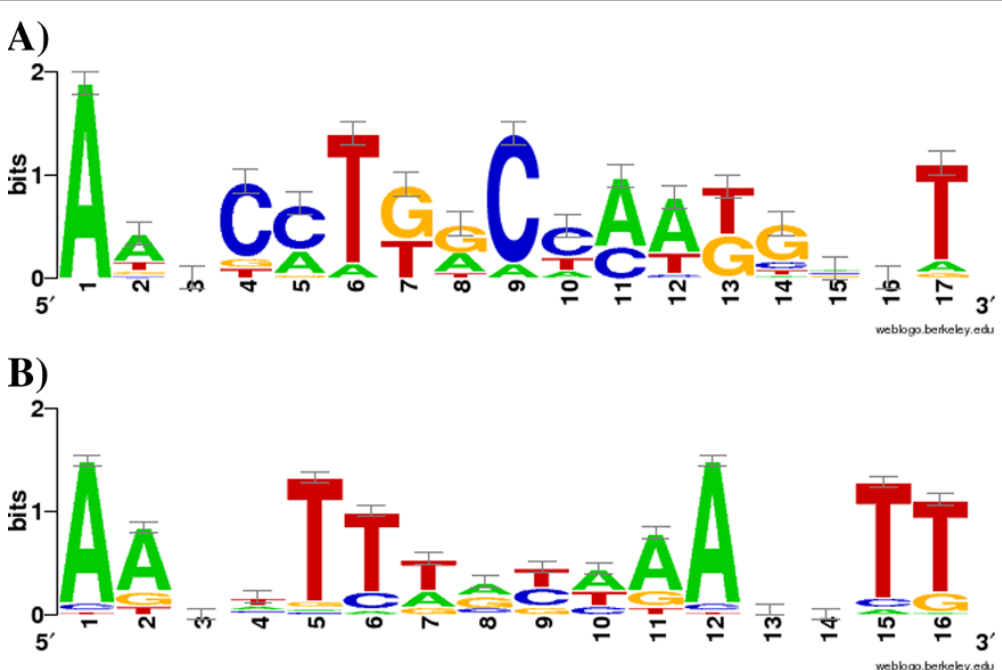

Figure 4 Putative regulatory module identified upstream of common-responsive genes. The motif is represented by a sequence logo generated by the WebLogos software [52]. 


\section{Correlation of transcriptomic and proteomic analyses} While it is well-known that RNA expression and protein abundance are not always correlated well $[55,56]$, we have presented evidences above that overall cellular responses identified from transcripomics and proteomics are very similar: responses such as induction of common stress response, transporters, cell envelope proteins and photosynthesis were observed in both proteomic and transcriptomic datasets. To further compare the proteomic and transcriptomic datasets quantitatively, twenty-three common genes/proteins up-regulated in both transcriptomics and proteomics datasets were plotted together (Figure 5). The results also showed very similar trends of up-regulation, with only five genes up-regulated in transcriptomic data, but almost no change in proteomics dataset (i.e. sll1423, ssl0707, slr0947, slr2143 and sll1892). However, no gene/protein with opposite regulation direction was found. In Saccharomyces cerevisiae, it has been proposed that there are three potential reasons for the lack of a strong correlation between transcriptomic and proteomic datasets: $i$ ) translational regulation, $i$ ) difference in protein half-lives in vivo and iii) significant levels of experimental error, including differences with respect to the experimental conditions being compared $[57,58]$. The inconsistence between transcriptomic and proteomic datasets also highlighted that it may not be enough to analyze biological systems only at a single level.

\section{Validation of the potential resistance targets by mutant strains}

Two genes, slr0724 and sll1392 which were found induced by ethanol exposure at $72 \mathrm{~h}$ for 1.5-2.0 and 4.05.0 folds, respectively (Table 3, Additional file 3: Table S3), were selected for construction of knockout mutants and for validation of their involvement in ethanol resistance. slr0724 encodes a HtaR suppressor protein homo$\log (\operatorname{soh} A$, or $\operatorname{prlF})$ according to CYORF Cyanobacteria Gene Annotation Database (http://cyano.genome.ad.jp/), and sll1392 encodes a regulatory gene, designated as $p f s R$ (photosynthesis, Fe homeostasis and stressresponse regulator) [59]. After confirmation by PCR and sequencing analysis, the mutants were grown in parallel with wild type Synechocystis sp. PCC 6803 in both normal BG11 medium and the BG11 medium supplemented with $1.5 \%$ ethanol. Comparative analysis showed that although there is no visible difference in terms of growth
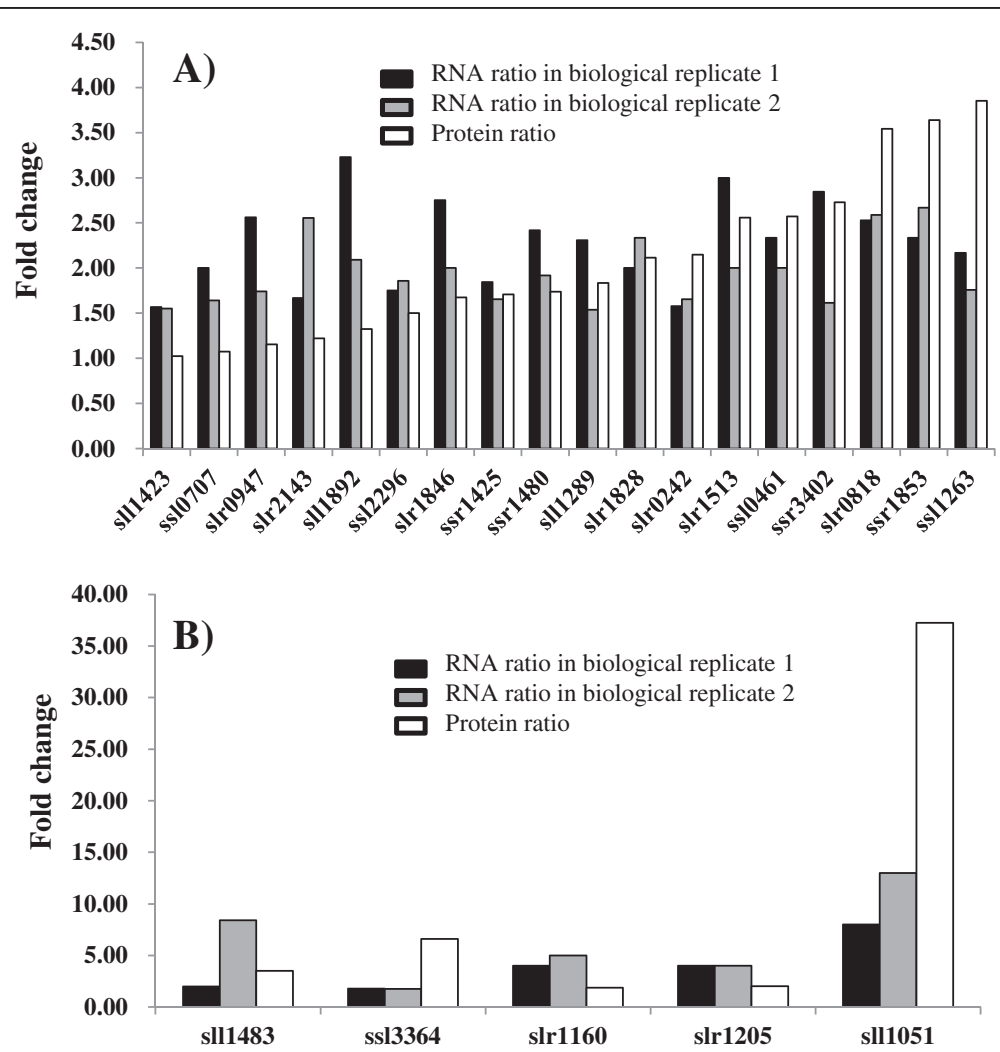

Figure 5 Comparison of ratios derived from RNA-Seq based transcriptomics with those from proteomics for up-regulated genes/ proteins by ethanol. A) Responsive genes/proteins with fold change smaller than 5.0; B) Responsive genes/proteins with fold change greater than 5.0. 
patterns between the wild type and the mutants in BG11 medium (Figure 6A), the slr0724 and sll1392 mutants grew slower than the wild type under $1.5 \%$ ethanol (Figure 6BC), suggesting that the mutants are more sensitive to ethanol, and the gene slr0724 and sll1392 may be involved in ethanol resistance. In addition, the results also showed that the growth difference between the wild type and the mutants became more significant at the late growth phases (i.e. 60-72 h), consistent the transcriptomic results that both genes were up-regulated only at $72 \mathrm{~h}$ (Table 3, Additional file 3: Table S3). According to NCBI annotation (NCBI accession ID: NP_439991.1), the slr0724 gene could be involved in protein secretion and it induces growth defect when overproduced or mutated; however, under our growth condition, no difference in terms of growth was observed between the mutant and the wild type strains (Figure 6A). In addition, the PrlF mutation was found to induce the activity of the Lon protease. In prokaryotic cells the ATP-dependent proteases Lon are involved in the turnover of misfolded proteins and the degradation of regulatory proteins, and depending on the organism, these proteases contribute variably to stress tolerance [60,61]. Early studies have shown that lon mutants of Campylobacter jejuni grow poorly at high temperature [60] and Lon protease is involved in the control of the SOS response, acid tolerance and nutritional deprivation in Escherichia coli [61]. It still needs more proof whether the similar biological process was also functional in PCC6803 against ethanol. An early study has found that the sll1392 ( $p f s R)$ deletion mutants were less sensitive to iron limitation under low light conditions and to suffer less lipid peroxidation following exposure to high light, suggesting a critical role of PfsR in regulation of iron homeostasis and stress response [59]. It may worth further investigation of the relationship between ethanol stress and iron homeostasis in Synechocystis sp. PCC 6803.

\section{Conclusions}

To fully elucidate microbial metabolism and its responses to ethanol, it is necessary to include functional characterization and accurate quantification of all levels of gene products, mRNA, proteins and even metabolites [54]. While high-throughput 'omics' approaches to analyze molecules at different cellular levels are rapidly becoming available, it is also becoming clear that any single 'omics' approach may not be sufficient to characterize the complexity of biological systems. To provide confirmation to previous proteomic analysis and also to reveal more responses at transcriptional level, in the study, we applied a quantitative RNA-Seq based transcriptomics approach combined with quantitative reverse-transcript PCR (RT-PCR) analysis to reveal the global transcriptomic responses to ethanol in Synechocystis sp. PCC 6803. The results showed that Synechocystis probably employed multiple and synergistic resistance mechanisms in dealing with ethanol stress. In addition, we found that the overall cellular responses inferred from transcriptomic and proteomic analyses were very similar, although the responsive genes were not always the same. By constructing knockout mutants and analyzing their ethanol tolerance, we have provided preliminary validation that the targets identified by the study could be used to obtain ethanol-tolerant cyanobacterial hosts by genetic engineering in Synechocystis sp. PCC 6803. Finally, our results showed that gene knockout of the potential targets individually caused only partial loss of the ethanol tolerance, consistent with the early conclusion that microbes tend to employ multiple resistance mechanisms in dealing with stress of single biofuel product $[7,8]$. With the ethanol-tolerance gene targets discovered from this study and previously
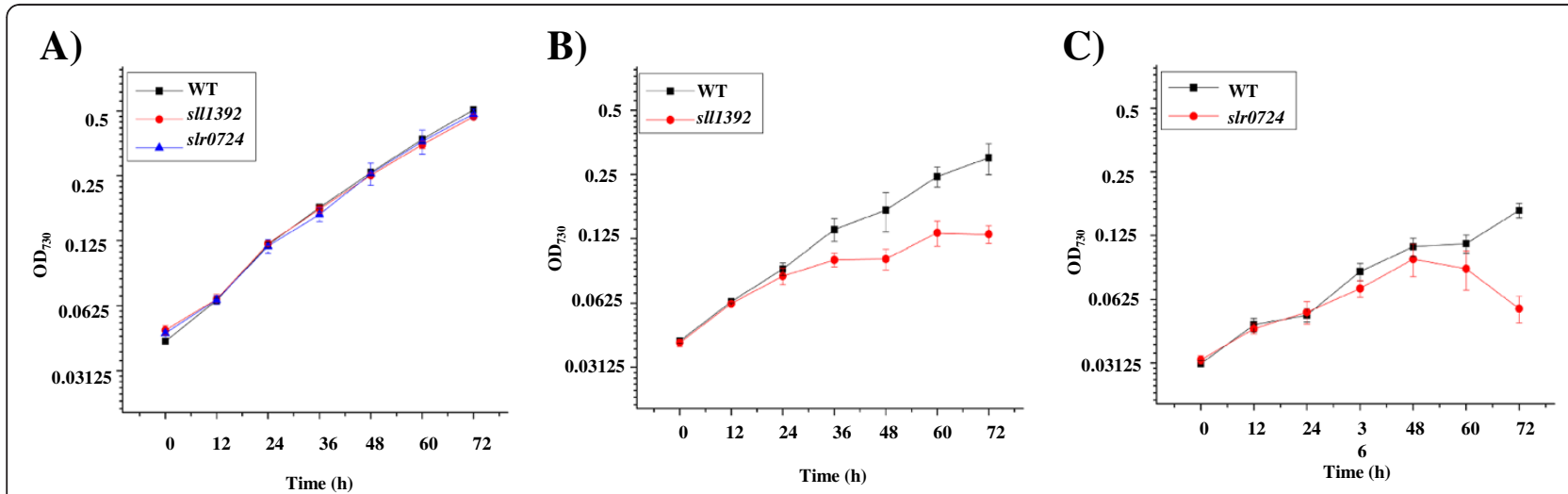

Figure 6 Ethanol tolerance analysis of mutant strains. A) Growth time courses of wild type, s/l1392 and s/r0724 mutants in BG11 medium; B) Growth time courses of wild type and s/1392 mutant in BG11 supplemented with 1.5\% ethanol; C) Growth time courses of wild type and slro724 mutant in BG11 supplemented with $1.5 \%$ ethanol. 
proteomic analysis [9], it may be possible to engineer multiple gene targets from different cellular functional categories simultaneously to achieve high-tolerance hosts in the future.

\section{Methods}

Bacterial growth conditions and ethanol treatment

Synechocystis sp. PCC 6803 was grown in BG11 medium $(\mathrm{pH} 7.5)$ under a light intensity of approximately 50 $\mu \mathrm{mol}$ photons $\mathrm{m}^{-2} \mathrm{~s}^{-1}$ in an illuminating incubator of $130 \mathrm{rpm}$ at $30^{\circ} \mathrm{C}$ (HNY-211B Illuminating Shaker, Honour, China). Cell density was measured on a UV1750 spectrophotometer (Shimadzu, Japan). For growth and ethanol treatment, $10 \mathrm{~mL}$ fresh cells at $\mathrm{OD}_{730}$ of 0.5 collected by centrifugation and then were inoculated into $50 \mathrm{~mL}$ BG11 liquid medium in a $250-\mathrm{mL}$ flask. Ethanol of varying concentration was added at the beginning of cultivation. $1 \mathrm{~mL}$ of culture samples were took and measured (OD730) every $12 \mathrm{~h}$. Morphology of Synechocystis sp. PCC6803 control and ethanol-treated samples was observed using a BX43 fluorescence microscope (Olympus, Japan). Cells for transcriptomics analysis were collected by centrifugation at $8,000 \times \mathrm{g}$ for 10 $\min$ at $4^{\circ} \mathrm{C}$.

\section{RNA preparation and CDNA synthesis}

Approximately $10 \mathrm{mg}$ of cell pellets were frozen by liquid nitrogen immediately after centrifugation and cell walls were broken with mechanical cracking at low temperature. Cell pellets were then resuspended in Trizol reagent (Ambion, Austin, TX) and mixed well by vortex. Total RNA extraction was achieved using a miRNeasy Mini Kit (Qiagen, Valencia, CA). Contaminating DNA in RNA samples was removed with DNase I according to the instruction in the miRNeasy Mini Manual (Qiagen, Valencia, CA). The RNA quality and quantity were determined using Agilent 2100 Bioanalyzer (Agilent, Santa Clara, CA) and subjected to cDNA synthesis. The RNA integrity number (RIN) of every RNA sample used for sequencing was more than 8.0. For each sample, 500 ng total RNA were subjected to cDNA synthesis using a NuGEN Ovation ${ }^{\circledR}$ Prokaryotic RNA-Seq System according to manufacturer's protocol (NuGEN, San Carlos, CA). The resulting double-stranded cDNA was purified using the MinElute Reaction Cleanup Kit (Qiagen, Valencia, CA).

\section{RNA-seq library preparation}

The double-stranded cDNA obtained was subjected to library preparation using the Illumina TruSeqTM RNA Sample Preparation Kit (Illumina, San Diego, CA), through a four-step protocol of end repairing, adding adenylate 3' ends, adapter ligation, and cDNA template enrichment. Amplification program is: $98^{\circ} \mathrm{C} 30 \mathrm{~s} ; 98^{\circ} \mathrm{C} 10 \mathrm{~s}$, $60^{\circ} \mathrm{C} 30 \mathrm{~s}, 72^{\circ} \mathrm{C} 30 \mathrm{~s}$ for 15 cycles; $72^{\circ} \mathrm{C}$ for $5 \mathrm{~min}$, and then hold at $4^{\circ} \mathrm{C}$. To determine the quality of the libraries, a Qubit ${ }^{\circledR}$ 2.0 Fluorometer and Qubit ${ }^{\mathrm{mu}}$ dsDNA HS (Invitrogen, Grand Island, NY) were first used to determine the DNA concentration of the libraries, and then FlashGel DNA Cassette (Lonza, USA) or Agilent Technologies 2100 Bioanalyzer (Agilent, Santa Clara, CA) was used to determine the product size of the libraries, with good libraries typically around $300 \mathrm{bp}$. The product was used directly for cluster generation using Illumina's Solexa Sequencer according to the manufacturer's instructions.

\section{Next-generation sequencing}

RNA $2 \times 100$ bp paired-end sequencing was performed using Illumina's Solexa Genome Analyzer II using the standard protocol. The cDNA library of each sample was loaded to a single lane of an Illumina flow cell. The image deconvolution and calculation of quality value were performed using Goat module (Firecrest v.1.4.0 and Bustard v.1.4.0 programs) of Illumina pipeline v.1.4. Sequenced reads were generated by base calling using the Illumina standard pipeline.

\section{Transcriptomics data analysis}

Sequence reads were pre-processed using FASTX Toolkit (Version: 0.0.13) to remove low-quality bases, and reads shorter than $20 \mathrm{bp}$. The qualified sequence reads were then mapped to non-coding RNA (ncRNA) sequences using Bowtie (Version: 2.0.0) with default settings. Genome sequences (including $n c$ RNA sequences) and annotation information of Synechocystis sp. PCC 6803 were downloaded from NCBI and the Comprehensive Microbial Resource (CMR) of TIGR (http://www. tigr.org/CMR) (Downloaded on April 22, 2012) [10]. Reads that mapped to $n c$ RNA sequences were excluded from further analysis. For paired-end Illumina reads, both pairs were removed if either pair mapped to rRNA. Remaining reads were mapped to the Synechocystis sp. PCC 6803 genome using Bowtie (Version: 2.0.0) with the default parameters. For gene expression determination, we performed a standard calculation of Reads Per Kilobase of Gene Per Million Mapped Reads (RPKM) based on the following formula [13]:

\section{$\mathrm{RPKM}=$}

transcription_reads

transcription_length X total_assembly_reads_in_run

$$
\times 10^{9}
$$

in which "transcription_reads" stands for the number of reads mapped to a given gene; transcription_length stands for gene length; and "total_mapped_reads_in_run" stands for the total number of reads in a given measurement. For each time point, two biological replicates of 
ethanol-treated samples and their control were analyzed and the corresponding gene expression ratios based on RPKM were calculated, the genes with 1.5 fold changes in both biological replicates were determined as differentially regulated genes.

\section{Quantitative real-time RT-PCR analysis}

The RNA samples were collected from cells grown under the same growth condition as described above for transcriptomic analysis. Approximately $10 \mathrm{mg}$ of cell pellets were frozen by liquid nitrogen immediately after centrifugation and cell walls were broken with mechanical cracking at low temperature. Cell pellets were then resuspended in Trizol reagent (Ambion, Austin, TX) and mixed well by vortex. Total RNA extraction was achieved using a miRNeasy Mini Kit (Qiagen, Valencia, CA). First-strand cDNAs were synthesized using RevertAidTM Reverse Transcriptase (Fermentas, Glen Burnie, MD). cDNA was subjected to eight hundred fold dilutions, and $2 \mu \mathrm{l}$ of each dilution was used as template for following qPCR reaction. The qPCR reaction was carried out in $20 \mu \mathrm{l}$ reactions containing $10 \mu \mathrm{l}$ of $\mathrm{SYBR}^{\circledR}$ Green PCR Master Mix (Applied Biosystems, Foster City, CA), and $2 \mu \mathrm{l}$ of each PCR primer at $2 \mathrm{mM}$, employing the StepOnePlus $^{\text {Tx }}$ Real-Time PCR System (Applied Biosystems, Foster City, CA), under the following condition: $50^{\circ} \mathrm{C}$ for $2 \mathrm{~min}$ and $95^{\circ} \mathrm{C}$ for $10 \mathrm{~min}$, followed by 40 cycles of $95^{\circ} \mathrm{C}$ for $15 \mathrm{~s}$ and $60^{\circ} \mathrm{C}$ for $1 \mathrm{~min}$. Quantification of gene expression was determined according to standard process of RT-PCR which used serial dilutions of known concentration of chromosome DNA as template to make a standard curve. A total of 18 selected genes based on their differential expression patterns revealed by iTRAQ were selected for verification and the $r n p B$ gene $(6803 s 01)$ encoding RNase $\mathrm{P}$ subunit $\mathrm{B}$ was used as an internal control according to the previous publication [62]. Three technical replicates were performed for each gene. Data analysis was carried out using the StepOnePlus analytical software (Applied Biosystems, Foster City, CA). Briefly, the amount of relative gene transcript was normalized by that of $r n p B$ in each sample (wild type or mutant), using the following method:

$$
\begin{aligned}
R_{\text {relative gene expression of gene } x=} & 2^{(\mathrm{Ct} \text { control-Ct treated }) \text { of } x} \\
& / 2^{\left(\mathrm{Ct} \text { control }-\mathrm{Ct}_{\text {treated }}\right) \text { of } \operatorname{rnpB}}
\end{aligned}
$$

Then data was presented as ratios of the amount of normalized transcript in the treatment to that from the control. The gene ID and their related primer sequences used for real-time RT-PCR analysis were listed in Additional file 4: Table S4.

\section{Promoter analysis and motif identification}

The Gibbs Motif Sampler software from the Biometrics Laboratory of Wadsworth Center, (http://www.bayesweb. wadsworth.org/gibbs/gibbs.html), was used to identify matrix models describing DNA sequence motifs present upstream of genes responsive to ethanol treatment $[50,51]$. Regions representing approximately 500 base pairs of the DNA sequences upstream of the translational start site of genes responsive to ethanol stress were extracted from the NCBI genome database using the Regulatory Sequence Analysis Tools (RSAT) [63]. Both strands of each sequence were searched and possible motif locations were identified using the motif matrix score obtained from the Gibbs Motif Sampler software. The multilevel consensus sequence for each motif was then used to generate a sequence logo that is a graphical representation of nucleic acid multiple sequence alignment (http://www.weblogo.berkeley.edu/) [52].

\section{Construction and analysis of gene knockout mutants}

A fusion PCR based method was employed for the construction of gene knockout fragments [64]. Briefly, for the gene target selected, three sets of primers were designed to amplify a linear DNA fragment containing the chloramphenicol resistance cassette (amplified from a plasmid pACYC184) with two flanking arms of DNA upstream and downstream of the targeted gene. The linear fused PCR amplicon was used directly for transformation into Synechocystis sp. PCC 6803 by natural transformation. The chloramphenicol-resistant transformants were obtained and passed several times on fresh BG11 plates supplemented with $10 \mu \mathrm{g} / \mathrm{ml}$ chloramphenicol to achieve complete chromosome segregation (confirmed by PCR). Two genes, slr0724 and sll1392 that have been found differentially regulated by ethanol exposure, were selected for construction of gene knockout mutants. The mutants were confirmed by PCR and sequencing analysis. PCR primers for mutant construction and validation were listed in Additional file 4: Table S4. Comparative growth analysis of the wild type 6803 and the mutants were performed in 100-mL flasks each with $10 \mathrm{~mL}$ BG11 medium with or without $1.5 \%$ ethanol. Cultivation conditions are the same as described above. Growth analysis was performed in triplicates.

\section{Additional files}

Additional file 1: Table S1. Raw RNA-seq transcriptomics data.

Additional file 2: Table S2. Gene down-regulated by ethanol exposure. Additional file 3: Table S3. Induced genes encoding hypothetical proteins.

Additional file 4: Table S4. Primers used in this study. 


\section{Abbreviations}

Adh: Alcohol dehydrogenase; AGES: Advanced glycation end products; CMR: Comprehensive Microbial Resource; desA: Acyl-lipid desaturase; HL: High light; iTRAQ: Isobaric tag for relative and absolute quantitation; LCMS/MS: Liquid chromatography-tandem mass spectrometry; MG: Methylglyoxal; ncRNA: non-coding RNA; PHA: Polyhydroxyalkanoate; pdc: Pyruvate decarboxylase; PSII: Photosystem II; RPKM: Reads per kilobase of gene per million mapped reads; ROS: Reactive oxygen species;

RSAT: Regulatory sequence analysis tools; RT-PCR: Reverse-transcript PCR; TCS: Two-component system.

\section{Competing interest}

The authors declare that they have no competing interests.

\section{Authors' contributions}

JW, LC and WZ conceived of the study. JW, LC, JQ and WZ drafted the manuscript. JW, LC, and XT carried out cultivation and transcriptomics analysis. LC, JL, XR and SH carried out the RT-PCR, mutant construction and phenotypic analysis. SH finished the promoter analysis. JW, LC and WZ finish the statistical analysis for transcripomic data. All authors read and approved the final manuscript.

\section{Acknowledgements}

The research was supported by grants from National Basic Research Program of China ("973" program, project No. 2011CBA00803 and No. 2012CB721101) and National High-tech R\&D Program ("863" program, project No. SS2012AA023107). The authors would also like to thank Tianjin University and the "985 Project" of Ministry of Education for their generous supports in establishing the research laboratory.

Received: 21 September 2012 Accepted: 4 December 2012 Published: 21 December 2012

\section{References}

1. Farrell AE, Plevin RJ, Turner BT, Jones AD, O'Hare M, Kammen DM: Ethanol can contribute to energy and environmental goals. Science 2006, 311:506-508.

2. Dien BS, Cotta MA, Jeffries TW: Bacteria engineered for fuel ethanol production: current status. Appl Microbiol Biotechnol 2003, 63(3):258-266.

3. Antoni D, Zverlov W, Schwarz WH: Biofuels from microbes. Appl Microbiol Biotechnol 2007, 77:23-35.

4. Machado IM, Atsumi S: Cyanobacterial biofuel production. J Biotechnol 2012: [Epub ahead of print].

5. Deng $M$, Coleman J: Ethanol synthesis by genetic engineering in cyanobacteria. Appl Environ Microbiol 1999, 65:523-528.

6. Fu P: Genome-scale modeling of Synechocystis sp. PCC 6803 and prediction of pathway insertion. J Chem Technol Biotechnol 2009, 84:473-483.

7. Nicolaou SA, Gaida SM, Papoutsakis ETA: Comparative view of metabolite and substrate stress and tolerance in microbial bioprocessing: From biofuels and chemicals, to biocatalysis and bioremediation. Metab Eng 2010, 12:307-331.

8. Dunlop MJ: Engineering microbes for tolerance to next-generation biofuels. Biotechnol Biofuels 2011, 4:32.

9. Qiao JJ, Wang JX, Chen L, Tian XX, Zhang WW: Quantitative iTRAQ LC-MS/MS proteomics reveals metabolic response to biofuel ethanol in cyanobacterial Synechocystis sp. PCC 6803. J Proteome Res 2012, 11(11):5286-5300.

10. Kaneko T, Nakamura Y, Sasamoto S, Watanabe A, Kohara M, Matsumoto M, Shimpo S, Yamada M, Tabata S: Structural analysis of four large plasmids harboring in a unicellular cyanobacterium, Synechocystis sp. PCC 6803. DNA Res 2003, 10:221-228.

11. Croucher NJ, Thomson NR: Studying bacterial transcriptomes using RNA-seq. Curr Opin Microbiol 2010, 13(5):619-624.

12. Shai RM: Microarray tools for deciphering complex diseases. Front Biosci 2006, 11:1414-1424.

13. Anders $\mathrm{S}$, Huber W: Differential expression analysis for sequence count data. Genome Biol 2010, 11:R106.

14. Mrázek J, Bhaya D, Grossman AR, Karlin S: Highly expressed and alien genes of the Synechocystis genome. Nucleic Acids Res 2001, 29(7):1590-1601.
15. Das S, Roymondal U, Chottopadhyay B, Sahoo S: Gene expression profile of the cynobacterium Synechocystis genome. Gene 2012, 497(2):344-352.

16. Wegener KM, Welsh EA, Thornton LE, Keren N, Jacobs JM, Hixson KK, Monroe ME, Camp DG 2nd, Smith RD, Pakrasi HB: High sensitivity proteomics assisted discovery of a novel operon involved in the assembly of photosystem II, a membrane protein complex. J Biol Chem 2008, 283(41):27829-27837.

17. Singh $A K$, Sherman LA: Characterization of a stress-responsive operon in the cyanobacterium Synechocystis sp. strain PCC 6803. Gene 2002, 297(1-2):11-19.

18. Furumichi M, Sato $Y$, Omata T, Ikeuchi M, Kanehisa M: CYORF: community annotation of cyanobacteria genes. Genome Inform 2002, 13:402-403.

19. Flint $A$, Sun $Y Q$, Stintzi $A: C j 1386$ is an ankyrin-containing protein involved in heme trafficking to catalase in Campylobacter jejuni. J Bacteriol 2012, 194(2):334-345.

20. Xia JL, Wu S, Zhang RY, Zhang CG, He H, Jiang HC, Nie ZY, Qiu GZ: Effects of copper exposure on expression of glutathione-related genes in Acidithiobacillus ferrooxidans. Curr Microbiol 2011, 62(5):1460-1466.

21. Das PK, Bagchi SN: Role of bacterioferritin comigratory protein and glutathione peroxidase-reductase system in promoting bentazone tolerance in a mutant of Synechococcus elongatus PCC7942. Protoplasma 2012, 249(1):65-74

22. Li H, Jubelirer S, Garcia Costas AM, Frigaard NU, Bryant DA: Multiple antioxidant proteins protect Chlorobaculum tepidum against oxygen and reactive oxygen species. Arch Microbiol 2009, 191(11):853-867.

23. Dvornyk V, Vinogradova O, Nevo E: Long-term microclimatic stress causes rapid adaptive radiation of kaiABC clock gene family in a cyanobacterium, Nostoc linckia, from "Evolution Canyons" I and II, Israel. Proc Natl Acad Sci USA 2002, 99(4):2082-2087.

24. Ding J, Huang X, Zhang L, Zhao N, Yang D, Zhang K: Tolerance and stress response to ethanol in the yeast Saccharomyces cerevisiae. Appl Microbiol Biot 2009, 85(2):253-263.

25. Stanley D, Bandara A, Fraser S, Chambers PJ, Stanley GA: The ethanol stress response and ethanol tolerance of Saccharomyces cerevisiae. J Appl Microbiol 2010, 109(1):13-24.

26. Thiel T: Phosphate transport and arsenate resistance in the cyanobacterium Anabaena variabilis. J Bacteriol 1988, 70:1143-1147.

27. Verma SK, Singh HN: Evidence for energy-dependent copper efflux as a mechanism of $\mathrm{Cu}^{2+}$ resistance in the cyanobacterium Nostoc calcicola. FEMS Microbiol Lett 1991, 68:291-294.

28. Nomura M, Ishitani M, Takabe T, Rai AK, Takabe T: Synechococcus sp. PCC7942 transformed with Escherichia coli bet genes produces glycine betaine from choline and acquires resistance to salt stress. Plant Physiol 1995, 107:703-708.

29. Mikkat S, Hagemann M, Schoor A: Active transport of glucosylglycerol is involved in salt adaptation of the cyanobacterium Synechocystis $\mathrm{sp}$. strain PCC 6803. Microbiol 1996, 142:1725-1732.

30. Tong L, Nakashima S, Shibasaka M, Katsuhara M, Kasamo K: A novel histidine-rich CPx-ATPase from the filamentous cyanobacterium Oscillatoria brevis related to multiple-heavy-metal cotolerance. J Bacteriol 2002, 184:5027-5035.

31. Hermans MA, Neuss B, Sahm H: Content and composition of hopanoids in Zymomonas mobilis under various growth conditions. J Bacteriol 1991, 173:5592-5595.

32. Amiri RM, Yur'eva NO, Shimshilashvili KR, Goldenkova-Pavlova IV, Pchelkin VP, Kuznitsova El, Tsydendambaev VD, Trunova TI, Los DA, Jouzani GS, Nosov AM: J Expression of acyl-lipid Delta12-desaturase gene in prokaryotic and eukaryotic cells and its effect on cold stress tolerance of potato. J Integr Plant Biol 2010, 52(3):289-297.

33. Buddelmeijer N, Young R: The essential Escherichia coli apolipoprotein $\mathrm{N}$-acyltransferase (Lnt) exists as an extracytoplasmic thioester acyl-enzyme intermediate. Biochemistry-US 2010, 49(2):341-346.

34. Schmaler M, Jann NJ, Götz F, Landmann R: Staphylococcal lipoproteins and their role in bacterial survival in mice. Int J Med Microbiol 2010, 300(2-3):155-160.

35. Nogales J, Campos R, BenAbdelkhalek H, Olivares J, Lluch C, Sanjuan J: Rhizobium tropici genes involved in free-living salt tolerance are required for the establishment of efficient nitrogen-fixing symbiosis with Phaseolus vulgaris. Mol Plant Microbe In 2002, 15(3):225-232. 
36. Zhu J, Jäger K, Black T, Zarka K, Koksharova O, Wolk CP: HcwA, an autolysin, is required for heterocyst maturation in Anabaena sp. strain PCC 7120. J Bacterio/ 2001, 183(23):6841-6851.

37. Ayub ND, Tribelli PM, López NI: Polyhydroxyalkanoates are essential for maintenance of redox state in the Antarctic bacterium Pseudomonas sp. 14-3 during low temperature adaptation. Extremophiles 2009, 13(1):59-66.

38. Kadouri D, Jurkevitch E, Okon Y, Castro-Sowinski S: Ecological and agricultural significance of bacterial polyhydroxyalkanoates. Crit Rev Microbiol 2005, 31:55-67.

39. Taroncher-Oldenburg G, Nishina K, Stephanopoulos G: Identification and analysis of the polyhydroxyalkanoate-specific beta-ketothiolase and acetoacetyl coenzyme $A$ reductase genes in the cyanobacterium Synechocystis sp. strain PCC6803. Appl Environ Microbiol 2000, 66(10):4440-4448.

40. Pepper ED, Farrell MJ, Nord G, Finkel SE: Antiglycation effects of carnosine and other compounds on the long-term survival of Escherichia coli. Appl Environ Microbiol 2010, 76(24):7925-7930

41. Ferguson GP: Protective mechanisms against toxic electrophiles in Escherischia coli. Trends Microbiol 1999, 7(6):242-247.

42. Mustafiz A, Sahoo KK, Singla-Pareek SL, Sopory SK: Metabolic engineering of glyoxalase pathway for enhancing stress tolerance in plants. Methods Mol Biol 2010, 639:95-118.

43. Mutsuda M, Michel KP, Zhang X, Montgomery BL, Golden SS: Biochemical properties of CikA, an unusual phytochrome-like histidine protein kinase that resets the circadian clock in Synechococcus elongatus PCC 7942. J Biol Chem 2003, 278(21):19102-19110.

44. Hughes J, Lamparter T, Mittmann F, Hartmann E, Gärtner W, Wilde A Börner T: A prokaryotic phytochrome. Nature 1997, 386(6626):663.

45. Schmitz O, Katayama M, Williams SB, Kondo T, Golden SS: CikA, a bacteriophytochrome that resets the cyanobacterial circadian clock. Science 2000, 289(5480):765-768.

46. Kappell AD, van Waasbergen LG: The response regulator RpaB binds the high light regulatory 1 sequence upstream of the high-light-inducible hliB gene from the cyanobacterium Synechocystis PCC 6803. Arch Microbiol 2007, 187(4):337-342. Epub 2007 Feb 10.

47. Juntarajumnong W, Hirani TA, Simpson JM, Incharoensakdi A, Eaton-Rye JJ: Phosphate sensing in Synechocystis sp. PCC 6803: SphU and the SphSSphR two-component regulatory system. Arch Microbiol 2007, 188(4):389-402.

48. Azuma M, Osanai T, Hirai MY, Tanaka K: A response regulator Rre37 and an RNA polymerase sigma factor SigE represent two parallel pathways to activate sugar catabolism in a cyanobacterium Synechocystis sp. PCC 6803. Plant Cell Physiol 2011, 52(2):404-412.

49. Los DA, Zorina A, Sinetova M, Kryazhov S, Mironov K, Zinchenko W: Stress Sensors and Signal Transducers in Cyanobacteria. Sensors-Basel 2010, 10(3):2386-2415

50. Lawrence CE, Altschul SF, Bogouski MS, Liu JS, Neuwald AF, Wooten JC: Detecting subtle sequence signals: a Gibbs Sampling Strategy for multiple alignment. Science 1993, 262:208-214.

51. Thompson W, Rouchka EC, Lawrence CE: Gibbs recursive sampler: finding transcription factor binding sites. Nucleic Acids Res 2003, 31:3580-3585.

52. Crooks GE, Hon G, Chandonia JM, Brenner SE: WebLogo: a sequence logo generator. Genome Res 2004, 14:1188-1190.

53. Brown SD, Guss AM, Karpinets TV, Parks JM, Smolin N, Yang S, Land ML, Klingeman DM, Bhandiwad A, Rodriguez M Jr, Raman B, Shao X, Mielenz JR, Smith JC, Keller M, Lynd LR: Mutant alcohol dehydrogenase leads to improved ethanol tolerance in Clostridium thermocellum. Proc Natl Acad Sci USA 2011, 108(33):13752-13757.

54. Tabei Y, Okada K, Tsuzuki M: SIl1330 controls the expression of glycolytic genes in Synechocystis sp. PCC 6803. Biochem Biophys Res Co 2007 355(4):1045-1050.

55. Nie L, Wu G, Culley DE, Scholten JC, Zhang W: Integrative analysis of transcriptomic and proteomic data: challenges, solutions and applications. Crit Rev Biotechnol 2007, 27(2):63-75.

56. Zhang W, Li F, Nie L: Integrating multiple 'omics' analysis for microbial biology: application and methodologies. Microbiology 2010, 156(Pt 2):287-301.

57. Greenbaum D, Colangelo C, Williams K, Gerstein M: Comparing protein abundance and mRNA expression levels on a genomic scale. Genome Biol 2003, 4:117.1-117.8.
58. Nie L, Wu G, Brockman FJ, Zhang W: Integrated analysis of transcriptomic and proteomic data of Desulfovibrio vulgaris: zero-inflated Poisson regression models to predict abundance of undetected proteins. Bioinformatics 2006, 22(13):1641-1647.

59. Jantaro S, Ali Q, Lone S, He Q: Suppression of the lethality of high light to a quadruple $\mathrm{HLI}$ mutant by the inactivation of the regulatory protein PfsR in Synechocystis PCC 6803. J Biol Chem 2006, 281(41):30865-30874.

60. Cohn MT, Ingmer H, Mulholland F, Jørgensen K, Wells JM, Brøndsted L: Contribution of conserved ATP-dependent proteases of Campylobacter jejuni to stress tolerance and virulence. Appl Environ Microbiol 2007, 73(24):7803-7813.

61. Langklotz S, Narberhaus F: The Escherichia coli replication inhibitor CspD is subject to growth-regulated degradation by the Lon protease. Mol Microbiol 2011, 80(5):1313-1325.

62. Kloft N, Rasch G, Forchhammer K: Protein phosphatase PphA from Synechocystis sp. PCC 6803: the physiological framework of PII-P dephosphorylation. Microbiology 2005, 151(Pt 4):1275-1283.

63. van Helden J: Regulatory sequence analysis tools. Nucleic Acids Res 2003, 31:3593-3596.

64. Wang $\mathrm{HL}$, Postier $\mathrm{BL}$, Burnap RL: Optimization of fusion PCR for in vitro construction of gene knockout fragments. Biotechniques 2002, 33(1):26. 28, 30 .

doi:10.1186/1754-6834-5-89

Cite this article as: Wang et al:: RNA-seq based identification and mutant validation of gene targets related to ethanol resistance in cyanobacterial Synechocystis sp. PCC 6803. Biotechnology for Biofuels 2012 5:89.

\section{Submit your next manuscript to BioMed Central and take full advantage of:}

- Convenient online submission

- Thorough peer review

- No space constraints or color figure charges

- Immediate publication on acceptance

- Inclusion in PubMed, CAS, Scopus and Google Scholar

- Research which is freely available for redistribution 